\title{
Modeling Financial Incentives to Get Unemployed Back to Work
}

\author{
Jan Boone* \\ Jan C. van Ours ${ }^{\dagger}$
}

December 19, 1999

\begin{abstract}
We model how unemployment benefit sanctions - benefit reductions that are imposed if unemployed do not comply with job search guidelines - affect unemployment. In our analysis we find that not only micro effects concerning the behavior of individual unemployed workers are relevant, but also macro-spillover effects from the additional creation of vacancies, which originates from the increased effectiveness of labor supply. We advocate that for a given loss in welfare for the unemployed benefit sanctions are more effective in reducing unemployment than an across the board reduction in the replacement rate.
\end{abstract}

JEL codes: H55, J65, J68

Keywords: unemployment benefits, financial incentives, sanctions.

The authors want to thank Jim Albrecht, Zvi Eckstein, Peter Fredriksson, Bertil Holmlund, Susan Vroman, participants of the December 1999 Labor Search Workshop at the Tinbergen Institute, participants of the September 1999 European Symposium in Labor Economics in Ammersee and especially Lans Bovenberg for useful comments.

${ }^{*}$ Department of Economics, Tilburg University, CentER and CPB Netherlands Bureau for Economic Policy Analysis; email: J.Boone@kub.nl.

${ }^{\dagger}$ Department of Economics, Tilburg University, CentER, Institute for Labor Studies (OSA), IZA and CEPR; email: vanours@kub.nl.

Address: Department of Economics, Tilburg University, P.O. Box 90153, NL-5000 LE Tilburg, The Netherlands. 


\section{Introduction}

Unemployment and especially long-term unemployment is high in may OECDcountries. The main problem is that workers stay unemployed for too long (see for example Layard, Nickell and Jackman (1991) and Bean (1994)). The lack of financial incentives for unemployed workers to get back to work may an important explanation of this phenomenon.

According to Nickell (1997) unemployment is high in countries that have reasonably generous unemployment benefits with very long periods of entitlement and little in the way of active policies to push unemployed into work ${ }^{1}$. The Netherlands and the United Kingdom are among the few European countries where unemployment went down substantially in recent years ${ }^{2}$. According to Nickell and Van Ours (1999, 2000) one of the reasons why the labor market performance in the Netherlands and the UK is so much better than in the rest of Europe is the restructuring of the benefit system to strengthen financial incentives for unemployed workers.

According to Ljungqvist and Sargent (1995) the unemployment rate in Sweden was low for many decades despite high unemployment benefits because of a policy of intensive control to prevent abuse. Ljungqvist and Sargent (1998) advocate that without strict policies to monitor search behavior of unemployed welfare states are not robust because high unemployment benefits prevent rapid adjustment of the economy in case of negative macroeconomic shocks.

Many OECD countries are moving towards more active labor market policies. There are several policies to stimulate long-term unemployed to get back to work. These policies are related to the loss of skills experienced by unemployed, to the transparency of the labor market or to financial incentives. Frequently used policies are education, training and temporary work projects to increase the ability of unemployed to work, job search programs to help unemployed find vacant slots and systems of bonuses and benefit sanctions to increase the willingness of unemployed to work. As we will illustrate in the next section, in some OECD countries

\footnotetext{
${ }^{1}$ High unemployment is associated with particular types of unionization and wage bargaining, with high taxes on labor and with poor educational standards at the bottom end of the labor market (Nickell (1997)).

${ }^{2}$ In the Netherlands the average unemployment rate in 1998 was 4.0\%, while in 1994 it was with $7.5 \%$ about twice as large. There is still a serious problem in the Netherlands concerning the numbers of workers collecting disability benefits (8-9 \% of the population aged 16-64 years). Although this is a large amount it has not increased during the 1990s, so the decline in unemployment is not because of a shift towards more workers collecting disability benefits. The unemployment rate in the UK went down from $10.5 \%$ in 1993 to $6.2 \%$ in 1998 .
} 
the latter type of policy is not used very often although in other countries it is used frequently. As the population in OECD countries ages and the labor market becomes tight, benefit sanctions may become attractive from a political point of view. Indeed, monitoring of the search intensity of unemployed workers may be the most direct way to address the moral hazard problems associated with unemployment insurance and to reconcile efficiency and equity.

In this paper we model the effects of financial incentives to get unemployed back to work. We focus on benefit sanctions. Within the framework of a Mortensen-Pissarides type of macro model of the labor market ${ }^{3}$ we analyze the effects of benefit reductions that are imposed if unemployed do not comply with job search guidelines. Although there is micro-evidence of the effects of financial incentives on the transition from unemployment to employment ${ }^{4}$, the implications of a system of benefit sanctions for total unemployment are not clear. There are several issues that cannot be studied in a micro context:

- Changes in the structure of the system: all unemployed face the same structure, so it is difficult to find out what the effects are if the parameters of the system (penalty, sanction rate) are changed.

- The ex ante effect of a benefit system: the mere possibility that unemployed workers may get a sanction affects their search behavior even before a sanction actually is imposed.

- Crowding-out effects: if all unemployed increase their search intensity the effect for an individual unemployed is substantially smaller than in the case that only a few unemployed increase their search intensity.

- Macro-spillover effects: if unemployed search more intensively it is worthwhile for employers to open more vacancies, which will reduce unemployment.

- Tax effects: if unemployment goes down taxes or social security contributions will be reduced, which will stimulate economic activities and further reduce unemployment.

The macro model that we build, allows us to identify and quantify each of these effects.

In the current paper our main interest is in the relationship between total unemployment and both the intensity with which unemployed are sanctioned and the amount by which benefits are reduced. Although our paper is related to work on the optimal time structure of unemployment benefits, this is not our

\footnotetext{
${ }^{3}$ See Mortensen and Pissarides (1999) for a general overview.

${ }^{4}$ See Atkinson and Micklewright (1991) for an overview of the effects of benefits and Abbring et al. (1997) and Van den Berg et al. (1998) for evidence on the micro effect of benefit sanctions. We discuss these studies in more detail below.
} 
main issue. Our main message is that there is a variety of ways in which financial incentives may be used to get unemployed into jobs. Financial incentives can be increased by lowering benefits or by introducing a system of benefit sanctions. We advocate that when financial incentives for unemployed are to be increased, the introduction of a system of sanctions is a good alternative to lowering the level of benefits in general.

The intuition is that an across the board reduction in the replacement rate increases search and lowers unemployment by making the unemployed worse off. With risk averse workers this is a costly way to reduce unemployment in terms of overall welfare. Introducing sanctions stimulates search partly through making the unemployed worse off and partly through the entitlement effect. That is, unemployed agents without a sanction search harder to avoid the sanction. Also, unemployed agents with a sanction search harder to find a job, because when they lose that job they will be entitled again to the full unemployment benefits (without a penalty). This entitlement effect makes sanctions more effective in reducing unemployment for a given loss in welfare for the unemployed than an across the board reduction in the replacement rate.

The paper is organized as follows. In Section 2 we give an overview of previous research related to our study. In Section 3 we model individual search behavior and the way this is affected by benefit sanctions. In Section 4 we discuss the relationship between individual search behavior and the labor market. In Section 5 we present results of simulations in which we change the structure of financial incentives. Section 6 concludes. The proofs of the results can be found in the appendix.

\section{Financial incentives and the labor market}

\subsection{Benefit sanctions in OECD countries}

Workers that collect unemployment benefits have to comply with administrative rules. In many countries to remain eligible for unemployment benefits, workers have to be available to start work at short notice, they have to provide proof of job search efforts (e.g. recent job applications), they are not allowed to reject job offers too easily and they have to attend interviews and training courses as required by the public employment services $^{5}$. These eligibility criteria may be

\footnotetext{
${ }^{5}$ These eligibility criteria refer to behavior during benefit periods. Apart from that, many countries also have criteria with respect to the behavior before benefits starts, especially with respect to efforts to prevent job loss.
} 
enforced by imposing benefit sanctions.

Table 1 gives an overview of sanction rates $^{6}$, replacement rates and unemployment rates across a number of OECD countries. The sanction rates range from very low in Sweden to quite high in the Netherlands and Switzerland. The Swedish system is sometimes considered as one where there is pressure on the unemployed, including possible denial of benefit, to both look for work and accept suitable job offers. Nevertheless, Björklund and Holmlund (1991) report that the yearly benefit denials amount to no more than approximately 1 and 2 percent of all who receive unemployment compensation during a year. As shown in Table 1 , in recent years it was even less than that. So, whereas the Swedish system is known for its activating labor market policy, in terms of benefit sanctions they are the least strict of all the OECD countries represented in Table 1, and they have the highest replacement rates. The Dutch and Swiss systems seem to be the most strict in terms of sanction rates, but they have relatively high replacement rates. In the US high sanction rates are combined with low replacement rates.

The sanction rates only give a rough approximation of the sanction systems. It is not only the percentage of benefit recipients that get a sanction imposed that is important. Also the strictness of labor market eligibility criteria and the type of criteria that matter. In Denmark and Finland for example criteria with respect to job search intensity are not enforced very strictly, but these countries have very strict rules for young workers when it comes to targeted labor market programs. In Switzerland the rules with respect to what type of job an unemployed worker should accept are not very strict, meaning that unemployed are allowed to refuse job offers outside their direct specialization, but the Swiss are very strict on the search process. Like in the UK, in Switzerland there are explicit guidelines about the reporting process and the minimum acceptable frequency of job applications or other acts of job search (see Grubb (1999) for further details).

Despite all the variation in sanction systems, the sanction rates do give some indication about the strictness of the way eligibility criteria are enforced. Table 1 also shows that there is a large variation in unemployment rates, from a low $4 \%$ in the Netherlands to a high $11.4 \%$ in Finland. All in all, there seems to be a positive relationship between the replacement rate and unemployment and there seems to be a negative relationship between the sanction rate and unemployment.

\footnotetext{
${ }^{6}$ These refer to sanctions because of behavior during benefit periods. The sanction rate is defined as sanctions during benefit periods as a percentage of the average stock of benefit claims. Apart from that there are sanctions for example because of lack of effort to prevent job loss (voluntary unemployment). In terms of the flow of initial benefit claims these sanctions range from 3.4\% in Finland to $13.5 \%$ in the US. See Grubb (1999) for details on the system of benefit sanctions in various countries.
} 
Of course the number of observations is too small to make strong statements about these types of relationships, but they are in line with the observations in Nickell and Van Ours $(1999,2000)$ that reduced benefits and stricter work tests are important elements of the decline in unemployment in both the UK and the Netherlands.

For the Netherlands we have information about the development in the sanction rate since 1987. This development, together with the development in the unemployment rate are shown in Figure 1. In the early 1980s the unemployment rate in the Netherlands increased from $5 \%$ to $12 \%$ in the time span of a couple of years. Because of this, it was decided to restructure the system of social security. Whereas income support had always been the primary aim of social security, from then on there was an increasing interest in stimulating re-employment of benefit recipients. In 1987 there was a major restructuring of unemployment benefits, sickness benefits, disability benefits and welfare benefits. The unemployment benefit replacement rates were lowered from 80 to $70 \%$ and eligibility rules were tightened. Furthermore, a system of benefit sanctions was introduced. In the first year, 1987, about 27,000 unemployment benefit sanctions were imposed, of which 12,000 were because of lack of effort to keep a job. The 15,000 benefit sanctions because of non-compliance with search rules implied a sanction rate of about 10\%. Over the years the sanction rate increased to about $15 \%$ in 1995 . In August 1996 a new law on benefit sanctions was introduced, which caused a further increase of the sanction rate to about $35 \%$ in $1997^{7}$. Figure 1 also shows that the unemployment rate decreased from $7.5 \%$ to $4 \%$ in the period 1994-1998.

From recent micro studies on the effect of benefit sanctions in the Dutch labor market we know that a reduction of unemployment benefits may have a substantial effect on the outflow from unemployment to a job. Abbring, Van den Berg and Van Ours (1997) study the effect of financial incentives by comparing the unemployment duration of individuals that have faced a benefit reduction with similar individuals that have not been penalized. They find that benefit sanctions have a positive effect on individual transition rates from unemployment to a job. The job finding rates double after a sanction has been imposed. Van den Berg, Van der Klaauw and Van Ours (1998) perform a similar study for welfare recipients in the city of Rotterdam. Although this group of unemployed has a labor market position that is often considered to be very weak they too find that benefit sanctions stimulate the transitions from welfare to work. Again, the job finding rate doubles at the imposition of a sanction.

\footnotetext{
${ }^{7}$ In terms of the inflow of benefit recipients the sanction rate concerning lack of effort to prevent job loss fluctuated but was never higher than $6.5 \%$.
} 
Ashenfelter et al. (1999) present an analysis of a field experiment to investigate whether stricter enforcement and verification of work search behavior decreases unemployment claims and benefits paid. If unemployed workers failed to meet the search requirements they would have lost their benefit (temporary or permanent). Ashenfelter et al. (1999) basically investigate whether there is an ex ante effect of benefit sanctions ${ }^{8}$. They find no such effect and conclude that the enforcement of sanctions is not worth the cost. In a study for 5 U.S. states Burgess (1992) find that usual non-compliance with unemployment-insurance job-search regulations is usually very low with an average non-compliance rate of $2 \%$. However, if monitoring is intensified the real non-compliance rate turns out to be in the neighborhood of $20 \%$.

\section{$2.2 \quad$ Related studies}

Our paper presents a macro model of the labor market in which unemployed are monitored to prevent and punish abuse of benefits (see Holmlund (1997) for a survey of labor market oriented studies of unemployment insurance). Unemployed workers receive a benefit at the start of their unemployment spell. We assume that they choose an optimal search intensity conditional on search costs, the labor market situation and the probability that they get a benefit reduction if their search intensity is too low. So, workers with too low a search intensity face a stochastic reduction of their benefit. The benefit level is constant over the duration of unemployment unless a sanction is imposed. If a sanction is imposed the benefit level is reduced but is again constant over the remaining unemployment spell. Our model is related to a variety of previous studies.

Fredriksson and Holmlund (1998) for example analyze the effect of a benefit reduction in a similar way. However, in their model they want to investigate the effect of an institutional reduction of unemployment benefits after a specific duration. They model a stochastic reduction of the benefit level as a practical solution to avoid problems related to non-stationary search in case the date of the reduction is fixed in advance.

In the model by Ljungqvist and Sargent (1995) the government exercises control over unemployed workers by stating a 'suitable' wage. This is a wage threshold level which, if offered and refused, triggers refusal of unemployment compensation to an unemployed worker. The government is assumed to have a stochastic

\footnotetext{
${ }^{8}$ Black et al. (1998) is a related study in the sense that here too an ex ante effect is investigated. In this case it is about mandatory employment and training programs. The study finds that some unemployed workers that are informed about these mandatory programs leave unemployment before they have to enter these programs. So, they do find an ex ante effect.
} 
monitoring technology. At low chances of escaping detection, the involuntarily unemployed (eligible for unemployment compensation) workers choose not to take any risks and accept all wage offers greater than or equal to the suitable wage. If the probability of avoiding detection rises the involuntarily unemployed worker will successively become choosier in their decision to accept a wage offer. According to the model, the government's control over the unemployed has been a major factor in the exceptionally low rate of unemployment in Sweden prior to the crisis. Direct controls have been used to counteract the distorted incentives from a generous unemployment compensation. In a situation of very high unemployment these government controls are less effective. The idea that high unemployment rates are associated with limited government enforcement abilities is incorporated by letting the parameter that represents the probability of detection to be a negative function of the unemployment rate. That is, for given government expenditures on operating unemployment agencies, a higher unemployment rate is associated with lower monitoring probability.

In Ljungqvist and Sargent (1998) a general equilibrium search model is formulated in which workers' skills depreciate during unemployment spells, and unemployment benefits are determined by workers' past earnings. The stochastic depreciation of skills during unemployment is twice as fast as the accumulation of skills. Both papers by Ljungqvist and Sargent $(1995,1998)$ formulate a policy of benefit sanctions based on government stipulated suitable wages. If unemployed workers reject a wage offer that exceeds such a suitable wage and this behavior is observed, then they loose their benefits.

Our paper is also related to research on the optimal structure of unemployment benefits. One of the issues here is how the benefits should vary over the duration of the unemployment spell. In the model of Shavell and Weiss (1979) the government optimizes the welfare of the unemployed under a budget restriction. They show that if unemployed have no control over their job finding rate it is optimal to have a constant benefit. If unemployed can control the job finding rate through their search activities, it is optimal to have benefits decline over the duration of unemployment. Hopenhayn and Nicolini (1997) have a similar model in which they introduce a wage tax that is imposed after unemployed enter a job. In their model benefits should decline over the duration of unemployment, while the wage tax should increase with the duration of the unemployment spell. Davidson and Woodbury (1997) have a model in which unemployed choose a search intensity that maximizes their lifetime income. They consider a labor market in which there are both unemployed workers with benefits and unemployed without benefits. The latter group of unemployed has exhausted entitlement to unemployment 
benefits because these were limited in duration. Since there are two groups of unemployed that compete for jobs there are spill-over effects. Unemployed without a benefit have a higher job finding rate if the benefit level is increased since this will induce workers with benefits to reduce their search intensity. In the model of Davidson and Woodbury there is an inverse relationship between the maximum benefit duration and the replacement rate: if the maximum duration is less than 32 weeks, the optimal replacement rate is larger than one. A final example of a study that considers the optimal structure of unemployment benefits is Cahuc and Lehmann (1997). In their model wage negotiations are important. If benefits would decline over the duration of the unemployment spell the bargaining power of the short term unemployed and of the insiders would increase, which would lead to higher wages and an increase in unemployment. It is therefore optimal to have constant unemployment benefits.

The impact of unemployment benefits on the exits out of unemployment has also been the topic of a lot of empirical research based on micro data. Usually, this research is focused on a comparison of unemployment durations of individuals with different levels of unemployment benefits (see Devine and Kiefer (1991) for an overview). There is a wide variety in the characteristics of the studies performed. Some studies deal with the benefit level, other studies also include the duration of the benefits, the distinction between unemployment benefits and unemployment assistance, the difference in behavior between unemployed that collect benefits and others that do not, etcetera. Some studies only consider exits out of unemployment, while other studies take the destination of the exit into account. A lot of the studies conclude that there is a modest effect of benefits on unemployment durations, but the results are not robust (Atkinson and Micklewright (1991), Devine and Kiefer (1993)). Alternatively, the effect of financial incentives is studied by means of social experiments. Meyer (1995) gives an overview of evaluations of unemployment insurance reforms in the United States, many of which have had an experimental nature. The unemployment insurance experiments mainly concern cash bonuses and job search programs. From the bonus experiments it appears that economic incentives do affect the speed with which unemployed workers leave unemployment, i.e. reduce the duration of unemployment. ${ }^{9}$

Benefit sanctions are assumed to be effective because of the financial incentive

\footnotetext{
${ }^{9}$ Experiments in which unemployed workers are exposed to different regimes of job search monitoring also show that intensive monitoring has positive effects: it reduces the receipt of unemployment benefits, increases earnings after unemployment and has benefits that exceed costs.
} 
related to them. It not clear that this is the only way in which they work. In a study on unemployment in The Netherlands, Gorter en Kalb (1996) find that just by giving attention to unemployed workers employment offices stimulate them to find a job more quickly ${ }^{10}$. Dolton and O'Neill (1996) find effects of the so-called Restart experiments in the UK, where unemployment benefit claimants were obliged to attend meetings with a counsellor to receive advice on for example search behavior and training courses. In the British Restart experiment, a random sample of individuals who had been unemployed for exactly six months were assigned to a control group and excused from receiving the 15-25 minutes interview and counseling session normally required at that time. By contrast, the treatments risked losing their benefits if they failed to attend the interview or demonstrate that they were available for work. After one year, those assigned to the control group had employment rates that were 4 percentage points lower than those in the treatment group, and for males this impact persisted for at least five years. Dolton and O'Neill conclude that such interventionist government policy can lead to a substantial reduction in time spent unemployed. From psychological research it appears that welfare fraud is not only determined by the expected punishment but also by the nature of the individuals. Some people do not enter welfare because of the social stigma attached to it (Yaniv (1997)). Therefore, the effect of a sanction could also be related to a stigma component. In our model we omit those non-pecuniary effects and assume that a sanction works through the financial stimulus. Along the line of Becker (1968) we assume that whether or not an unemployed complies with job search guidelines depends on the balance of benefits and costs of such a behavior. This means that unemployed will comply if the punishment is severe or the expected probability of being caught is high.

As indicated in the introduction we are especially interested in effects that go beyond the effects measured in micro-studies. The traditional evaluation literature usually defines the effect of participation to be the effect of the program on participants explicitly enrolled in the program. These are 'direct effects'. They exclude the effects of a program that do not flow from direct participation, known as the 'indirect effects'. In evaluation studies usually indirect effects are ignored. Whether this is valid requires constructing a model of the labor market. Examples are Davidson and Woodbury $(1993,1995)$ who within the framework of a Mortensen-Pissarides model present an attempt to analyze the indirect effects of an unemployment bonus program. They assume that prices and wages are

\footnotetext{
${ }^{10}$ Note that Van den Berg and Van der Klaauw (1999) conclude from an analysis of data from a field experiment that counseling and monitoring alone is not sufficient to influence the job finding rate of Dutch unemployed workers.
} 
fixed and consider the effects of the bonus program on the search behavior of participants and nonparticipants. The reemployment bonus scheme accelerates the rate at which unemployed persons offered the bonus find job. The bonus is paid to currently unemployed eligible persons with spells below a threshold level who find jobs within a specified time frame. Because of the enhanced search by those with the subsidy, the rate of job acquisition declines for those currently ineligible for the bonus. Davidson and Woodbury estimate that 30-60 percent of the gross employment effect of the bonus program is offset by displacement of workers ineligible for unemployment insurance.

In a model with flexible skill prices, Heckman, Lochner and Taber (1998) consider the effects of changes in tuition on schooling and earnings, accounting for general equilibrium effects on participants and nonparticipants. They show that conventional practices in the educational evaluation literature lead to estimates of enrollment responses that are ten times larger than the long-run general equilibrium effects. Newly trained workers may displace previously trained workers if wages are inflexible, as they are in many European countries. For some training programs in Europe, substantial displacement effects have been estimated. Calmfors (1994) presents a comprehensive review of the issues that arise in evaluating active labor market programs in the context of a modern economy. $\mathrm{He}$ distinguishes a number of indirect effects. First there are displacement effects since jobs created by one program are at the expense of other jobs. Then there are deadweight effects because labor market programs subsidize hiring that would have occurred anyway in the absence of the program. There are also substitution effects because jobs created for a certain category of workers replace jobs for other categories because relative wage costs have changed. Finally, there are the effects of taxation required to finance the programs on the behavior of everyone in society. A central conclusion is that the estimates of program impact from the microeconomic treatment literature provide incomplete information about the full impacts of labor market policies.

\section{Individual search behavior and benefit sanc- tions}

Our model captures the idea that the government may want to punish the lack of search effort of unemployed in order to give them a higher incentive to find 
a job. ${ }^{11}$ The scheme works as follows. Once a worker becomes unemployed, he receives an unemployment benefit that is constant over the unemployment spell unless he gets a sanction imposed. If he is found to be searching too little he is punished with a sanction, that is a permanent reduction in the unemployment benefit level he receives. We assume that a worker can only be punished once. This is in line with the empirical observation that multiple sanctions are a rare event (Abbring, Van den Berg and Van Ours (1997)).

Let $b_{u}=b w$ denote the unemployment benefit level of someone without a sanction. The benefit level of someone that has been confronted with a punitive benefit reduction equals $b_{p}=(1-p) b w$. Let $V_{u}$ denote the value of being unemployed without being sanctioned; $V_{p}$ the value of being sanctioned and $V_{e}$ the value of being employed.

A worker can invest search time (or intensity) $s \in[0,1]$ to find a job. The disutility of searching for a time $s$ equals $\gamma(s)$, with $\gamma(0)=0, \gamma^{\prime}(0)=0, \gamma^{\prime}(s)>$ $0, \gamma^{\prime \prime}(s)>0, \gamma^{\prime \prime \prime}(s)>0$ and $\lim _{s \rightarrow 1} \gamma^{\prime}(s)=+\infty$. In the simulations below, we use the following search cost function

$$
\gamma(s)=\frac{1-(1-s)^{1-\kappa}}{1-\kappa}-s
$$

with $0<\kappa<1$. The Poisson arrival rate of a new job is equal to $\mu s$ for the unemployed both with and without a sanction. As explained in the macro part below, $\mu$ is increasing in the number of vacancies. That is, the more vacancies are posted, the higher the return to search $s$.

The sanction system is modeled in the following way. We want to capture the idea that monitoring search intensity is not straightforward. That is, any search monitoring system is likely to be imperfect in the sense that, on the one hand, agents who search at the socially optimal level can be punished with a sanction, while, on the other hand, agents who do not search enough can get away with it unpunished. The point is that it is hard to measure an agent's search intensity in practice. However, it is reasonable to assume that the higher an agent's search intensity the lower the probability that he will be punished. Modeling the probability of being sanctioned as a Poisson arrival rate $\lambda(\sigma-s)$

\footnotetext{
${ }^{11}$ We start from the observation that in OECD countries the government provides unemployment insurance. In principle, it may be possible (or even better) that unemployment insurance is provided by private firms or that individuals save money in the capital market to insure themselves against employment loss. Our model sheds no light on who should provide the insurance. But as long as agents share the risk of unemployment through insurance, the moral hazard problem with respect to search intensity exists. To reduce this moral hazard problem one can reduce the replacement rate or introduce sanctions.
} 
with $\lambda>0$ and $\sigma \geq 1$ captures these ideas in a simple way. Further, note that in the case with $\lambda, p>0$, taking the limit $\sigma \longrightarrow+\infty$ makes the sanction system equivalent to an across the board reduction in the replacement rate. A property that will be used below.

For simplicity we assume that all jobs offer the same wage $w$ net of taxes and that $w>b w>0$ such that each worker who finds a job accepts it. Unemployed have only one instrument of search, their search intensity. We could introduce a second instrument of search, the reservation wage, by assuming a distribution of wages. Then the unemployed could also determine the optimal reservation wage. However the basic results of our model would not change to a large extent.

The firm and the worker bargain about the wage rate. A matched firmworker combination produces $y$ units of (non-storable) output which are sold at (numeraire) price 1 . There is an exogenous rate of job separation $\delta$ and workers and firms discount the future at rate $\rho$.

Agents value money income $w$ with a concave felicity function $\frac{w^{1-\zeta}}{1-\zeta}$ with $\zeta \geq 0$. The case $\zeta=0$ corresponds to risk neutrality, while the agents are risk averse for $\zeta>0$. This risk-aversion assumption is needed because otherwise the optimal unemployment benefit level is zero and there is no need to analyze the effects of sanctions. Note that due to the concavity of the felicity function, agents on a low income have a bigger incentive to increase this income than agents on a high income (that is, decreasing marginal utility of income). Finally, we assume that firms are risk neutral.

We denote the value for the worker of being employed (unemployed) by $V_{e}$ $\left(V_{u}\right)$ and the value for the firm of employing a worker (posting a vacancy) by $J_{e}$ $\left(J_{v}\right)$. Then these values satisfy the following Bellman equations:

$$
\begin{aligned}
\rho V_{e} & =\frac{w^{1-\zeta}}{1-\zeta}+\delta\left(V_{u}-V_{e}\right) \\
\rho J_{e} & =y-(1+\tau) w-\tau_{a}+\delta\left(J_{v}-J_{e}\right) \\
\rho J_{v} & =-c+\frac{\mu(\theta)}{\theta}\left(J_{e}-J_{v}\right)
\end{aligned}
$$

where total taxes paid by the firm equal $\tau w+\tau_{a}$, the (per period) cost of posting a vacancy equals $c$ and $\theta$ denotes labor market tightness. This variable $\theta$ is endogenized in the macro part of the model. Here one should note that the probability that a firm is matched with a worker, $\frac{\mu(\theta)}{\theta}$, is decreasing in labor market tightness $\theta$.

Equation (2) says that the value of being employed for a worker equals the utility from the wage he receives each period plus the probability $\delta$ that the match is dissolved in which case he becomes unemployed and receives $V_{u}$ instead of $V_{e}$. 
Equation (3) gives the value for a firm of employing a worker. This equals the value of output $y$ minus total wage $\operatorname{costs}(1+\tau) w+\tau_{a}$ plus the probability $\delta$ that the match is dissolved and the firm has to post a vacancy. The value for the firm of posting a vacancy is given by equation (4). It equals minus the cost of posting a vacancy $c$ plus the probability that the firm is matched with a worker, in which case it receives $J_{e}$ instead of $J_{v}$. We assume free entry into the job creation business, that is $J_{v}=0$.

To determine the wage, we use the Nash bargaining solution. The bargaining power of the firm is denoted by $\beta \in\langle 0,1\rangle$ and the bargaining power of the worker by $(1-\beta)$. Then the net wage $w$ solves

$$
\max _{w}\left(\frac{\frac{w^{1-\zeta}}{1-\zeta}}{\rho+\delta}+\frac{\delta}{\rho+\delta} V_{u}-V_{u}\right)^{1-\beta}\left(\frac{y-(1+\tau) w-\tau_{a}}{\rho+\delta}+\frac{\delta}{\rho+\delta} J_{v}-J_{v}\right)^{\beta}
$$

Assume that the unemployment benefit level $b_{u}=b w$ is defined on the economy wide average wage $w$. Then an individual worker's choice of wage $w$ does not affect the unemployment benefit level he will receive when he becomes unemployed. That is, $\frac{\partial V_{u}}{\partial w}=0$ in the Nash bargaining function. The first order condition for $w$ can now be written as

$$
\beta(1+\tau)\left(\frac{w^{1-\zeta}}{1-\zeta}-\rho V_{u}\right)=(1-\beta) w^{-\zeta}\left(y-(1+\tau) w-\tau_{a}\right)
$$

or equivalently

$$
\frac{w^{1-\zeta}}{1-\zeta}=\frac{\beta}{1-(1-\beta) \zeta} \rho V_{u}+\frac{1-\beta}{1-(1-\beta) \zeta} \frac{y-\tau_{a}}{1+\tau} w^{-\zeta}
$$

The higher the worker's bargaining power (the lower $\beta$ ) the higher his share of the after-tax surplus $\frac{y-\tau_{a}}{1+\tau}$. In case the workers have full bargaining power $(\beta=0)$ the wage is equal to the total after tax surplus. In case the employers have full bargaining power $(\beta=1)$ the wage is such that the utility derived from it equals the discounted value of unemployment $\left(\frac{w^{1-\zeta}}{1-\zeta}=\rho V_{u}\right)$. As the worker becomes more risk averse ( $\zeta$ increases) the wage decreases. This is a well known property of the Nash bargaining outcome.

Using the free entry condition for firms, $J_{v}=0$, the wage is determined by

$$
\frac{w^{1-\zeta}}{1-\zeta}=\rho V_{u}+\frac{1-\beta}{\beta(1+\tau)}(\rho+\delta) \frac{\theta c}{\mu(\theta)} w^{-\zeta}
$$

which for given $\theta$ and $\rho V_{u}$ gives a unique solution in $w$. Due to the free entry condition into vacancy creation, the total surplus a worker and firm can divide is the search cost for the firm $\frac{\theta c}{\mu(\theta)}$. 
As noted above, in this section we take the macro variable $\theta$ as given and hence write $\mu$ instead of $\mu(\theta)$. Now one can derive the following Bellman equations for the agents, where $V_{p}$ denotes the value for an agent with a penalty.

$$
\begin{aligned}
\rho V_{u} & =\max _{0 \leq s \leq 1}\left[\frac{(b w)^{1-\zeta}}{1-\zeta}-\gamma(s)+\mu s\left(V_{e}-V_{u}\right)+\lambda(\sigma-s)\left(V_{p}-V_{u}\right)\right] \\
\rho V_{p} & =\max _{0 \leq s \leq 1}\left[\frac{[(1-p) b w]^{1-\zeta}}{1-\zeta}-\gamma(s)+\mu s\left(V_{e}-V_{p}\right)\right] \\
\rho V_{e} & =\rho\left(V_{u}+\frac{1-\beta}{\beta} \frac{w^{-\zeta}}{(1+\tau)} \frac{\theta c}{\mu}\right)
\end{aligned}
$$

The value of unemployment in equation (6) consists of three parts: the flow of utility during unemployment (utility of benefits minus search costs), the expected flow of additional income when a job is found and the expected (negative) income change when a sanction is imposed. We model agent's risk aversion on money income only. That is, agents cannot compensate low money income with low search costs. Hence, the disutility of the penalty-lottery cannot be diversified away by adjusting search intensity, which would be possible if utility were for instance specified as $\frac{\left(\frac{b w}{1+\gamma(s)}\right)^{1-\zeta}}{1-\zeta}$. The value of unemployment after a sanction is imposed is given in equation (7) and consists of two parts: the flow of utility during unemployment, which is now lower because of the penalty, and the expected flow of additional income after a job is found. The value of employment in equation (8) equals the value of being unemployed plus a 'share' of the surplus $\frac{\theta c}{\mu}$.

In the Nash bargaining function we do not distinguish between unemployed agents with and without a sanction. This is due to the following renegotiation proof argument. If an unemployed agent with a sanction bargains over the wage with a firm, his fall back position is $V_{p}$. But once he is hired by the firm, his fall back position is $V_{u}$ and he will renegotiate his wage immediately. Both the firm and the worker realize this, hence the wage is determined by $V_{u}$ for both types of unemployed agents. As our main result is that sanctions are more effective in raising employment than across the board reductions in the replacement rate, relaxing this assumption makes our argument stronger. In particular, if the wage of an unemployed worker with a sanction is bargained with $V_{p}$ as fall back position, the wage is lower than with $V_{u}$ as fall back position. Hence, more vacancies are created. This beneficial effect of sanctions on wages is not considered below.

The following result is useful for future derivations, as it gives a strict lower bound on $V_{p}$. The other inequalities are intuitive. Employment yields the highest 
utility, then being unemployed without a sanction and finally being unemployed with a sanction.

Lemma 1 Suppose $\mu, \theta, \lambda, c>0, b, p \in\langle 0,1\rangle, \tau \in[0,1]$ and $\beta \in\langle 0,1\rangle$ then $\rho V_{e}>\rho V_{u}>\rho V_{p}>\frac{[(1-p) b w]^{1-\zeta}}{1-\zeta}$.

The next result shows the conditions under which unemployed agents without a penalty search harder than agents with a penalty. Let $s_{u}$ denote the optimal search intensity in equation (6) and $s_{p}$ the optimal search intensity in equation (7).

Lemma 2 If $\lambda=\mu$ then $s_{p}=s_{u}$, if $\lambda>\mu$ then $s_{p}<s_{u}$ and if $\lambda<\mu$ then $s_{p}>s_{u}$.

The intuition for this result is as follows. There are two effects pulling in opposite directions. On the one hand, due to the penalty $p$ unemployed agents with a penalty search harder because their situation is worse than that of unemployed agents without a penalty, $V_{p}<V_{u}$. On the other hand, agents without a penalty search harder because they want to avoid the penalty, while for penalized agents there is no further penalty. In this model, these two effects exactly offset each other in case $\mu=\lambda$.

The difference between $s_{p}$ and $s_{u}$ is referred to as the ex post effect. ${ }^{12}$ That is, it measures the increase in search intensity of an unemployed worker after a sanction is imposed. Hence, the ex post effect is positive if $\lambda<\mu$. Note that the sign of the ex post effect does not depend on the size of the penalty $p$.

As described in the introduction, from empirical research we know that the job finding rate is substantially larger than the sanction rate (the ratio is something like 20). This means that $\mu s \gg \lambda(\sigma-s)$. So the situation that $\mu=\lambda$ only is a likely situation in case $s$ is large, so that workers search close to their maximum capacity. If this is not the case than the most likely situation is one in which $\mu>\lambda$ implying that $s_{p}>s_{u}$, unemployed search more intensively after a benefit sanction has been imposed.

The next lemma characterizes the solution to the Bellman equations (6)-(8) above in terms of $\left(V_{u}-V_{p}\right)$ and $w$.

Lemma 3 Solving the Bellman equations (6)-(8) boils down to solving the following equations in $x$ and $w$

\footnotetext{
${ }^{12}$ Recall that the ex ante effect is defined as the difference between $s_{u}$ with a sanction system and $s_{u}$ before a sanction system is introduced.
} 


$$
\begin{aligned}
& \left(1-b^{1-\zeta}\right) \frac{w^{1-\zeta}}{1-\zeta}-\frac{1-\beta}{\beta} \frac{w^{-\zeta}}{1+\tau}(\rho+\delta) \frac{c \theta}{\mu(\theta)} \\
= & \max _{0 \leq s \leq 1}\left\{-\gamma(s)+s \frac{1-\beta}{\beta} \frac{w^{-\zeta}}{1+\tau} \theta c-\lambda(\sigma-s) x\right\} \\
& \left(1-[(1-p) b]^{1-\zeta}\right) \frac{w^{1-\zeta}}{1-\zeta}-\frac{1-\beta}{\beta} \frac{w^{-\zeta}}{1+\tau}(\rho+\delta) \frac{c \theta}{\mu(\theta)} \\
= & \rho x+\max _{0 \leq s \leq 1}\left\{-\gamma(s)+s \frac{1-\beta}{\beta} \frac{w^{-\zeta}}{1+\tau} \theta c+\mu s x\right\}
\end{aligned}
$$

where $x \equiv V_{u}-V_{p}$. For any given set of parameters $\rho, \lambda, b, c, \beta, \theta, \mu$ and $p$ these two equations have a unique solution $(\hat{x}, \hat{w})$. Further, the optimal search intensities are given by

$$
\begin{aligned}
\gamma^{\prime}\left(\hat{s}_{u}\right) & =\frac{1-\beta}{\beta} \frac{\hat{w}^{-\zeta}}{1+\tau} \theta c+\lambda \hat{x} \\
\gamma^{\prime}\left(\hat{s}_{p}\right) & =\frac{1-\beta}{\beta} \frac{\hat{w}^{-\zeta}}{1+\tau} \theta c+\mu \hat{x}
\end{aligned}
$$

Now we can characterize the effects of $p, \lambda, b$ and $\sigma$ on the search intensities $s_{u}$ and $s_{p}$, for given $\theta$ and given taxes $\tau, \tau_{a}$ which are endogenized later on. These we interpret as the effects observed in the micro studies discussed in section 2. As these studies analyze small scale benefit sanction experiments, it is not unreasonable to assume that in these cases macro variables like $\theta, \tau$ and $\tau_{a}$ were unaffected. Further, we analyze the effect of an exogenous rise in $\theta$. The effect of $\theta$ on $w$ is needed below to prove the existence of an equilibrium.

Each of the parameters affect the search intensities directly and indirectly via the wage rate $(w)$ and the difference between value of being unemployed without and with a sanction $(x)$. A rise in $x$ causes both search intensities to go up: $s_{u}$ rises to avoid the loss $x$ and $s_{p}$ rises to recoup the loss $x$. The latter has been identified by Mortensen (1977) as the entitlement effect for the case where $p=1$. In Mortensen's paper a rise in the benefit level raises job search by noninsured agents. This is due to the fact that a rise in $b$ makes employment more attractive relative to non-insured unemployment, because a spell of employment is a prerequisite for benefit eligibility. With a slight abuse of terminology, we refer to a rise in $x$ which tends to raise search as the entitlement effect.

The effect of the wage rate on search only appears if workers are risk averse $(\zeta>0)$. As $w$ falls, the marginal utility of income in the unemployed state 
without and with a sanction $\left((b w)^{-\zeta}\right.$ and $((1-p) b w)^{-\zeta}$ respectively) rises. That is, agents value a rise in income more and thus search harder to find a job. ${ }^{13}$

Lemma 4 The following comparative statics hold for the system of equations (9)-(12), where $\theta$ is treated as an exogenous variable.

$\frac{d s_{u}}{d p}>0, \frac{d s_{p}}{d p}>0$;

$\frac{d s_{u}}{d \lambda}>0, \frac{d s_{p}}{d \lambda}<0$;

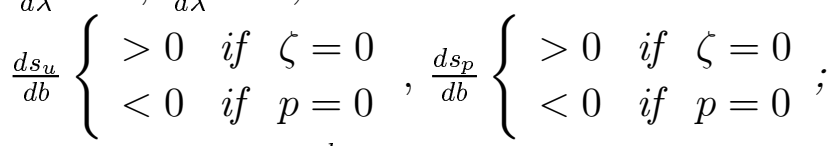

$\frac{d s_{u}}{d \sigma}<0$ if $\zeta=0, \frac{d s_{p}}{d \sigma}<0$;

$\frac{d s_{u}}{d \theta}>0, \frac{d s_{p}}{d \theta}>0$ and $\frac{d w}{d \theta}>0$.

The effect of an increase in the penalty on both search intensities is intuitively clear. If the penalty increases, the expected loss in income due to a sanction increases as well (the ex ante effect). This stimulates unemployed to increase their search intensity. If the penalty increases, the value of being unemployedwith-sanction decreases relative to the value of employment. This stimulates the unemployed to increase search intensity after a sanction is imposed. Further, the increase in the penalty reduces the wage rate by decreasing the worker's outside option $\left(V_{u}\right)$ in wage bargaining. If workers are risk averse $(\zeta>0)$, this fall in $w$ increases the marginal utility of unemployed workers with and without a sanction. This further stimulates search by the unemployed.

The effect of an increase in the sanction rate on search depends on whether or not a sanction has been imposed. If no sanction has been imposed then an increase in the sanction rate makes a rise in search more effective in avoiding the sanction. Hence, $s_{u}$ rises. This is strengthened by the effect that a rise in $\lambda$ (for given penalty $p>0$ ) reduces $V_{u}$ and hence $w$ (via wage bargaining). This raises the marginal utility of income and hence unemployed workers without a sanction search harder. These two effects outweigh the fall in $x$ caused by the rise in $\lambda$. However, once a sanction has been imposed, the sanction rate $\lambda$ has no direct effect on search $s_{p}$. Instead, the reduction in $x$ causes agents to search less, since there is less to gain by finding work. This effect outweighs the fall in $w$. Hence, unemployed workers with a sanction search less as $\lambda$ is increased.

The effect of $b$ on both search intensities is ambiguous, due to the following two effects. On the one hand, a rise in $b$ raises the difference in value between

\footnotetext{
${ }^{13}$ In the next section, $\theta$ is endogenised. Then such a fall in $w$ makes it more attractive for firms to open vacancies. Hence, $\theta$ rises which stimulates search further because $\frac{d s_{u}}{d \theta}, \frac{d s_{p}}{d \theta}>0$ as shown in the lemma.
} 
being unemployed without and with a sanction $(x)$, because this difference is driven by the size of the penalty $p b w$. This entitlement effect raises search. On the other hand, the rise in $b$ improves the worker's fall back position in wage bargaining and hence raises the wage. This rise in $w$ reduces the marginal utility of income and hence the unemployed search less. If $\zeta=0$, workers are risk neutral and the latter effect disappears. In that case, the entitlement effect causes a rise in search intensity. However, if $p=0$ (and thus $x=0$ ) the entitlement effect disappears and for $\zeta>0$ agents search less in response to a rise in $b$.

A rise in the transition rate to the penalty state $\sigma$ can be interpreted in two ways. One is that the government becomes less careful in imposing sanctions. In other words, the government makes more mistakes in sanctioning agents who, in fact, search hard enough. The other interpretation is to view the limit $\sigma \longrightarrow+\infty$ as an across the board reduction in the replacement rate. Raising $\sigma$ means that the two states (with and without a penalty) become more alike, that is $x$ falls. This reduces the entitlement effect and tends to reduce search $s_{u}$. However, the rise in $\sigma$ also reduces the wage rate (by reducing $V_{u}$ ) and hence increases the marginal utility of income. The entitlement effect dominates if $\zeta=0$. In this case a rise in $\sigma$ reduces $s_{u}$. The rise in $\sigma$ always reduces the search intensity of unemployed with a sanction, as the entitlement effect dominates the effect of the fall in $w$.

Finally, a rise in $\theta$ raises agents' search intensities through its direct effect on the job finding rate. In a tight labor market (high $\theta$ ), it pays to search hard for a job. Further, as the labor market becomes more tight, the fall back position of workers improves while the fall back position of employers deteriorates. This raises the wage $w$.

\section{Modeling the labor market}

In this section the macro variable $\theta$ is endogenized. Let $v$ denote the number of vacancies created. Then the tightness of the labor market is defined as $\theta \equiv \frac{v}{s_{u} u_{u}+s_{p} u_{p}}$, where $u_{x}$ denotes the number of unemployed in state $x=u, p$. Assuming that the matching function is of the form $m\left(s_{u} u_{u}+s_{p} u_{p}, v\right)=A\left(s_{u} u_{u}+s_{p} u_{p}\right)^{1-\eta} v^{\eta}$ with $\eta \in\langle 0,1\rangle$, the parameter $\mu$ in the equations above equals $\mu(\theta)=\frac{m\left(s_{u} u_{u}+s_{p} u_{p}, v\right)}{s_{u} u_{u}+s_{p} u_{p}}=$ $A \theta^{\eta}$. That is, $\mu$ equals the probability of a match per unit of search effort.

Equilibrium in the labor market is determined by demand and supply. To determine the demand for labor by firms, we repeat the assumptions made above. There is a cost $c$ of posting a vacancy. The Poisson arrival rate for a firm to get matched with a worker equals $\frac{m\left(s_{u} u_{u}+s_{p} u_{p}, v\right)}{v}=\frac{\mu(\theta)}{\theta}=A \theta^{-(1-\eta)}$. Once matched 
with a worker the firm produces $y$ units of output. The firm pays total wage $\operatorname{costs}(1+\tau) w+\tau_{a}$. And with exogenous probability $\delta$ the match is dissolved. As above, $J_{v}$ denotes the value of a firm posting a vacancy and $J_{e}$ the value of a firm employing a worker. Then the following Bellman equations can be derived.

$$
\begin{aligned}
\rho J_{v} & =-c+\frac{\mu(\theta)}{\theta}\left(J_{e}-J_{v}\right) \\
\rho J_{e} & =y-(1+\tau) w-\tau_{a}+\delta\left(J_{v}-J_{e}\right)
\end{aligned}
$$

Assuming free entry in posting vacancies yields $J_{v}=0$. Hence we find $J_{e}=$ $\frac{y-(1+\tau) w-\tau_{a}}{\rho+\delta}$. Substituting this in the equation for $J_{v}$ above yields

$$
w=\frac{y-\tau_{a}-(\rho+\delta) \frac{c \theta}{\mu(\theta)}}{1+\tau}
$$

which we interpret as the firm's demand for labor curve.

The next lemma shows that the model here has a unique solution, for given policy parameters. The proof uses the fact that equation (14) is downward sloping in $(\theta, w)$ space, while lemma 4 implies that equations (9)-(12) yield an upward sloping relation in $(\theta, w)$ space.

Lemma 5 For given policy parameters $\tau, \tau_{a}^{14}, b, \lambda, p$, the equations (9), (10), (11), (12) and (14) have a unique solution $\left(w, x, s_{u}, s_{p}, \theta\right)$.

Given the equilibrium values of $s_{u}, s_{p}$ and $\theta$ one can calculate the steady state distribution of agents $[0,1]$ over the three states of being unemployed without a penalty, $u_{u}$, unemployed with a penalty, $u_{p}$, and employed $e$. The following lemma shows this steady state distribution.

Lemma 6 In steady state

$$
\begin{array}{r}
u_{u}=\frac{\mu(\theta) s_{p} \delta}{\Delta} \\
u_{p}=\frac{\lambda \delta\left(\sigma-s_{u}\right)}{\Delta} \\
e=\frac{\mu(\theta) s_{p}\left(\mu(\theta) s_{u}+\lambda\left(\sigma-s_{u}\right)\right)}{\Delta}
\end{array}
$$

where $\Delta \equiv \lambda \delta\left(\sigma-s_{u}\right)+\mu(\theta) s_{p}\left(\delta+\mu(\theta) s_{u}+\lambda\left(\sigma-s_{u}\right)\right)$.

\footnotetext{
${ }^{14}$ Note that in the simulations, the taxes $\tau$ and $\tau_{a}$ adjust endogenously to keep the government budget constraint satisfied. In principle, this could yield multiple equilibria. In practice, however, this does not turn out to be a problem as the simulations converge to the same equilibrium independent of the initial guesses.
} 
In the simulations, a reduction in the replacement rate increases search intensity and decreases unemployment but to a lesser extent as the replacement rate falls. These diminishing returns in lowering the replacement rate are strongest in simulations with risk neutral workers (not reported here) but also appear in the simulations below (with risk averse workers) as shown in figure 3. This diminishing returns feature is one motivation to consider an alternative way to reduce unemployment, such as introducing a sanction system. The following proposition derives sufficient conditions for this diminishing returns property of across the board reductions in the replacement rate.

Proposition 7 Assume that the tax parameters $\tau$ and $\tau_{a}$ remain constant. Then in the situation without sanctions, $\lambda=x=0$, it is the case that $\frac{d u_{u}}{d b}>0$. Sufficient conditions for $\frac{d^{2} u_{u}}{d b^{2}}>0$ are $\eta=\zeta=0$ and $u_{u}<\frac{3}{4}$.

Note that these conditions are sufficient, not necessary, and that by continuity (and the fact that the functions involved here are well behaved) the result also holds for $\zeta$ and $\eta$ close to 0 . The intuition for this result sheds light on the mechanisms through which the replacement rate in the model affects unemployment. The intuition follows the proof in the appendix by considering the effect of $b$ on $u_{u}$ via $w, \theta$ and $s_{u}$. Note that with $\lambda=x=0$ it is the case that $u_{u}=\frac{\delta}{\delta+\mu(\theta) s_{u}}$.

As $b$ is reduced, for given tax parameters, the value of being unemployed falls. This reduces workers' outside option in bargaining with the firm and hence the wage falls. But for lower values of $w$ a given change in the replacement rate $b$ has a smaller effect on the level on unemployment benefits $b w$. Hence, as $b$ is reduced, its effect on the wage $w$ becomes smaller and smaller. There is one effect which goes in the opposite direction if workers are risk averse. Then as the replacement rate $b$ and benefits $b w$ go to zero, the marginal utility of income increases. Hence, a further reduction in $b$ leads to a big fall in workers' outside option and hence to a big fall in the bargained wage. This causes the effect of $b$ on $w$ to be bigger for lower values of $b$ and $w$. If workers are risk neutral, the latter effect disappears.

The way $b$ affects $\theta$ is via the wage rate $w$. Lower $w$ implies that firms get a bigger part of the surplus. This invites entry by firms and hence raises $\theta$. Such reductions in $b$ run into decreasing returns in terms of $\theta$, because the effect of $b$ on $w$ becomes smaller and smaller (if $\zeta$ is close to 0 ). However, there is an effect which causes reductions in $b$ to become more and more effective in raising $\theta$. To see this, differentiate equation (14) with respect to $w$, keeping $\tau$ and $\tau_{a}$ constant and using $\mu(\theta)=A \theta^{\eta}$. This yields

$$
\frac{d \theta}{d w}=-\frac{\theta^{\eta}}{1-\eta} \frac{A}{c} \frac{1+\tau}{\rho+\delta}
$$


Thus a reduction in $b$ decreases $w$ which raises $\theta$. This rise in $\theta$ is bigger, the higher $\theta$ is. In other words, although the effect of $b$ on $w$ becomes smaller as $b$ becomes smaller, the effect on $\theta$ becomes bigger the higher $\theta$ is. The equation shows that this latter effect plays a small role if $\eta$ is close to 0 .

A reduction in $b$ raises the unemployed agent's search effort, but less so as $b$ becomes smaller. This is due to the following two observations. First, the positive effect of $b$ on $\theta$ becomes smaller as $b$ is reduced. Second, the search cost function $\gamma($.$) features increasing marginal costs. Hence as b$ is reduced, the agent raises $s_{u}$ but to a smaller extent as $s_{u}$ becomes higher. If agents are risk averse, there is an effect working in the opposite direction. The smaller $b$, the smaller the unemployment benefit level $b w$ and hence the higher the marginal utility of income. A rise in the marginal utility of income raises workers' search efforts. If $\zeta$ is close to 0 , the latter effect is small and the effect of $b$ on search $s_{u}$ becomes smaller as $b$ falls.

Finally, a reduction in $b$ reduces unemployment at a decreasing rate. This is due to the results above that a reduction in $b$ has a smaller effect on $\theta$ and $s_{u}$ as $b$ becomes smaller. To see why the condition $u<\frac{3}{4}$ is needed, recall that $u_{u}=\frac{\delta}{\delta+\mu(\theta) s_{u}}$ and hence

$$
\frac{d u_{u}}{d\left(\mu(\theta) s_{u}\right)}=-u(1-u) \frac{1}{\mu(\theta) s_{u}}
$$

For values of $u_{u}$ close to 1 , a reduction in $u_{u}$ increases the effect of $\mu(\theta) s_{u}$ on unemployment $u_{u}$.

One of the main results of this paper is that penalties are more effective than a reduction in the replacement rate in stimulating employment $e$. In the simulations this is shown with endogenous tax rates to balance the government budget constraint. The next result shows this feature with exogenous tax rates.

Proposition 8 Assume that the tax parameters $\tau$ and $\tau_{a}$ remain constant. Consider a situation without sanctions, $\lambda=0$ but $p>0$. Then it is the case that: $\frac{d e}{d \lambda}>\left|\frac{d e}{d b}\right|$ under the condition that $\left|\frac{d w}{d \lambda}\right|=\frac{d w}{d b}$.

To understand the result, note that we need a condition to make the two measures comparable. That is, if the fall in replacement rate reduces $w$ (or equivalently, by equation (5), $V_{u}$ ) to a far bigger extent than the rise in $\lambda$ does, it is clear that the effect of $b$ on employment will be bigger. This is so, because the fall in $w$ increases search intensity directly by equation (11) and indirectly via a rise in $\theta$ because more vacancies are created in equilibrium. So we concentrate 
on the case where the replacement rate is reduced and $\lambda$ is increased to such an extent that the effect on $w$ is the same.

The intuition for the result is then as follows. For given reduction in $w$, both measures have the same direct effect on $s_{u}$. However, the threat of a penalty increases $s_{u}$ more if $\lambda$ is increased than if $b$ is reduced. This can be seen in equation (11). Further, both measures have the same effect on $\theta$ by equation (14). But raising $\lambda$ has a further effect because $x \equiv V_{u}-V_{p}>0$ as $p>0$. Finally, evaluating the rise in $\lambda$ around $\lambda=0$ implies that $\mu(\theta)>\lambda$. Hence it follows from lemma 2 that $s_{p}>s_{u}$. In words, agents with a sanction search harder than unemployed agents without a sanction (ex post effect). And workers without a sanction with the introduction of the sanction search harder than unemployed agents faced with a reduction in the replacement rate. These entitlement effects cause the employment effect of introducing sanctions to exceed the employment effect of reducing the replacement rate.

These results continue to hold when taxes are endogenized as shown in the simulations. However, then there is no longer an unambiguous analytical result because the reduction in the replacement rate may lead to bigger tax reductions than the introduction of a penalty.

In terms of welfare the advantage of a penalty system over a generic reduction in the replacement rate can be seen as follows. A reduction in the replacement rate stimulates search and reduces unemployment only through making the unemployed worse off. In other words, it works as a stick. With risk averse agents this is costly in terms of welfare. Beside a stick, a penalty system features a carrot in the form of the entitlement effect. Unemployed agents without a sanction search harder to avoid a sanction and unemployed agents with a sanction search harder to find a job, because a job entitles them again to full unemployment benefits (without a penalty) once they lose the job. This carrot allows the penalty system to shorten the stick, which yields a welfare gain with risk averse workers.

In the simulations below, this is illustrated in Figure 5. This shows that welfare is decreasing in $\sigma$ and converges to 3.135 as $\sigma$ tends to infinity. As argued above, the penalty system is equivalent to an across the board reduction in the replacement rate for $\sigma \longrightarrow+\infty$. However, the figure shows that welfare in decreasing in $\sigma$. Hence a penalty system with finite $\sigma$ is to be preferred above a generic reduction in the replacement rate. 


\section{Changing financial incentives}

\subsection{Benefit reductions and a benefit sanction system}

In this section we present and discuss alternative ways to increase financial incentives for unemployed to find jobs. In our baseline model we use parameter values that are in line with the Dutch labor market of the early 1990s. The characteristics of this Dutch labor market are well in line with those of other European countries in the same time period. Then, we investigate to what extent labor market indicators change as benefits are reduced or a system of benefit sanctions is introduced.

Although our model is in continuous time, our parameters are set to values that reflect a quarterly time dimension. The parameter values in our baseline model are the following:

Discount rate: $\rho=0.025$

Replacement rate: $b=0.70$

Sanction process: $\lambda=0.0$

Penalty: $p=0.0$

Search cost function: $\kappa=0.5$

Matching function: $\eta=0.5, A=1.0$

Wage negotiations: $\beta=0.5$

Production: $y=1$

Vacancy costs: $c=2$

Job destruction rate: $\delta=0.04$

Risk aversion: $\zeta=2$

Tax per match: $\tau_{a}=0$

The value of the discount rate $\rho$ is set to 0.025 , which is $10 \%$ on an annual basis and is quite common in these types of exercises. The value of the replacement rate $b$ is according to the official rule in the 1990s that unemployment benefits are $70 \%$ of the previous wage (see also Table 1 and the study by Martin (1996)). The effective replacement rate for individual unemployed may be higher or lower than $70 \%$. Since there is a so called social minimum benefit the replacement rate is higher when workers have had an income close to the minimum wage. Because there is also a maximum benefit workers that have previously earned a high wage have a replacement rate lower than $70 \%$. In our baseline model we assume that there is no system of benefit sanctions so both parameters of the sanction process $(\lambda$ and $p)$ are set to zero. The parameter $\kappa$ of the search cost function in equation (1) is set to 0.5. We have tried a range of values, but as long as this parameter is not too close to either 0 or 1 the simulation results do 
not change a lot. The parameter $\eta$ of the matching function is set to its usual value of 0.5 , which implies that unemployment and vacancies have a similar effect on the flow of filled vacancies ${ }^{15}$. The parameter $A$ of the matching function is set to be equal to 1 . This value was chosen in order to have an unemployment duration that is approximately in line with reality. The parameter $\beta$ of the wage negotiation process is set equal to 0.5 . Not only is this a very common assumption, it also implies that the parameter of the wage negotiation process is equal to the parameter of the matching function so that the efficiency condition of Hosios (1990) is fulfilled. The value of production $y$ is set to 1 , so the value of related variables like wages and taxes are normalized. The vacancy $\operatorname{costs} c$ are set to 2, implying that in every period the costs for having a vacancy are twice the value of production. Of course, the total cost of a vacancy also depend on the average vacancy duration. Furthermore, the job destruction rate $\delta$ is set to 0.04 , which implies that on an annual basis $16 \%$ of the jobs are destroyed. This number is in line with the number of workers that start on a new job each year. The parameter for risk aversion $\zeta$ is set to be equal to 2. In combination with the other parameters this leads to a maximal value for $V_{u}$ at a replacement rate of about 0.70 (see Figure 2$)^{16}$. Finally, we choose the tax parameter $\tau_{a}=0$. As shown in Boone and Bovenberg (1999) this is optimal in search models where the Hosios condition is satisfied and where vacancy $\operatorname{costs} c$ are constant. In particular, $c$ does not depend on the number of vacancies posted, $v$. The marginal wage tax $\tau$ is adjusted endogenously in the simulations to satisfy the government budget constraint

$$
e \tau w=u_{u} b w+u_{p} b(1-p) w
$$

where on the left hand side are the total wage tax revenues and on the right hand side the total government expenditures on unemployment benefits. ${ }^{17}$

The simulation results of our baseline-model are shown in the first column of Table 2. They indicate that with these parameter values we get a reasonable

\footnotetext{
${ }^{15}$ Broersma and Van Ours (1999) give an overview of recent empirical studies on the matching function. They find that a value of $\eta$ of 0.5 is a reasonable approximation.

${ }^{16}$ The from a welfare point of view optimal replacement rate is closely related to the degree of risk aversion. We experimented with a range of values from $\zeta=0.5$ to $\zeta=5.0$. At the lower bound the optimal replacement rate is 0.60 , at the upper bound it is 0.79 . When $\zeta=2.0$ we find an optimal replacement rate of 0.71 .

${ }^{17}$ We have also looked at the case with exogenous government spending $g>0$, but introducing this does not affect the results. Further, one can argue that setting up an agency which monitors agents' search intensity (as required under a sanction system) induces government spending as well. We come back to this point below.
} 
approximation of the Dutch labor market of the early 1990s. The unemployment rate is $8.7 \%$ and the vacancy rate is $2.1 \%^{18}$. It is clear from Table 2 that unemployed could search harder since their search intensity is about $70 \%$ but apparently there is no reason for them do so. ${ }^{19}$ Total welfare increases with search intensity to reach a maximum at 0.91, as shown in Figure 4. Comparing this optimum with the real search intensity in the first column of Table 2 it is obvious that unemployed workers have a search intensity that is far below the optimum from a welfare point of view.

There are two ways in which we can change the incentives for unemployed workers to search harder for a job sooner: lowering the replacement rate and introducing a system of benefit sanctions. Lowering the replacement rate is the most frequently used measure to increase incentives. Figure 2 indicates how changes in the replacement rate affect steady state welfare ${ }^{20}$ and $V_{u}$, the value of being unemployed. As is indicated $V_{u}$ has a maximum at a replacement rate of about 0.70 , while total welfare is at its maximum level at a replacement rate of about 0.63 . If the replacement rate gets very high both total welfare and $V_{u}$ drop substantially. It is obvious that starting from a replacement rate of 0.70 where we have a maximum value of $V_{u}$ total welfare can be increased by reducing the replacement rate. We return to this below.

Figure 3 shows what happens to search intensity and the unemployment rate if we vary the replacement rate. We know that lowering the replacement rate increases search intensity and reduces unemployment (see proposition 7). At higher replacement rates search intensity $s_{u}$ becomes very low and unemployment high. Further, proposition 7 implies that reducing the replacement rate reduces unemployment to a smaller extent as the replacement rate falls, as shown in Figure 3.

Now that we have shown the relationship between the replacement rate and

\footnotetext{
${ }^{18}$ The average vacancy duration is about 8 weeks, so that the cost per vacancy are about 1.2. this means that the cost of a vacancy are about 1.2 quarters of production value.

${ }^{19}$ Under these conditions the net wage is equal to 0.87 . Taking the taxes into account this means that the wage costs are equal to 0.94 , which is quite high compared to the value of production. The main reason for this is that all that employers need to cover in the production process is the wage costs and the value of opening a vacancy. Should we have included capital in the production process the employers would need a larger share of the value of production in order to cover for the investment in capital. However, the basic results of our simulations would not change because of this.

${ }^{20}$ Welfare $W$ is defined as: $u_{u} V_{u}+u_{p} V_{p}+e\left(V_{e}+J_{e}\right)+v J_{v}$, where $J_{v}=0$ by the free entry condition. Because of the value of the risk aversion parameter $W, V_{u}$ and $V_{p}$ are negative numbers. For reasons of presentation we added 15 to the simulated values of $W$ and $V_{u}$ and $\mathrm{V}_{p}$. Since $W, V_{u}$ and $V_{p}$ are indices this does not affect the nature of the simulation results.
} 
some economic indicators we will show what happens to all relevant labor market variables if we start changing the financial incentives. First, we will change the replacement rate and then we will show what happens if a system of benefit sanctions is introduced.

The second column of Table 2 shows for all relevant indicators what happens if the replacement rate is increased to 0.8. This value of the replacement rate was common for the Netherlands in the early 1980s and was changed to 0.7 in 1987. As shown, search intensity goes down to 0.6. Unemployment goes up to $12 \%$ and the vacancy rate goes down to $1.7 \%$. The high unemployment rate is in line with the Dutch labor market of the early 1980s (see Van Ours (1991) for an overview of the Dutch labor market characteristics of the early 1980s). Furthermore, because of increasing unemployment benefit expenditures, taxes go up and net wages go down. Overall welfare goes down and even the value of being unemployed is lower with the higher replacement rate.

The third column of Table 2 gives the effects of a reduction of the replacement rate to 0.63 , the value that is optimal from a welfare point of view. As is also clear from Figure 2 the value of being unemployed is lower with this lower replacement rate. Search intensity goes up and unemployment goes down to $7.3 \%$, while the vacancy rate goes up to $2.4 \%$. So, one can increase welfare and reduce unemployment by lowering the replacement rate. But with risk averse workers this generic reduction in the replacement rate is rather costly in terms of the value of being unemployed $V_{u}$.

The fourth column of Table 2 shows the effects of introducing a system of benefit sanctions. The system is introduced by setting the sanction parameter $\lambda$ equal to 0.50 and the penalty $p$ equal to $0.1^{21}$. The sanction parameter has to be combined with the search intensity to find the effective sanction rate. If, for example as in the fourth column of Table 2 , the search intensity $s_{u}=0.76$, then the effective sanction rate is equal to $(1-0.76)^{*} 0.50=0.12$, implying a sanction rate of $12 \%$ per quarter. However, since average unemployment duration is about 2.2 quarters, the share of unemployed workers that get a benefit sanction imposed is not very large. As indicated in Table 2 the share of unemployed with a benefit sanction is about $20 \%$, which is even somewhat low compared to some numbers presented in section 2. The search intensity before a sanction is imposed goes up from 0.71 to 0.76 , so the ex ante effect of a benefit sanction causes the search intensity to increase with $7 \%$. The search intensity after a sanction is imposed goes up from 0.76 to 0.77 , so the ex post effect also increases the search intensity

\footnotetext{
${ }^{21}$ We ignore for the moment the monitoring costs of the system of benefit sanctions. We discuss this issue in more detail in the next subsection.
} 
with $1.3 \%$. In other words, the ex post effect is substantially smaller than the ex ante effect.

Column 5 gives the simulation results for a different combination of $\lambda$ and $p$. If the penalty is increased from 0.1 to 0.5 the unemployment rate goes down to $6.3 \%$. Now, search intensity goes up to 0.91 in the pre-sanction period and to 0.93 after a sanction has been imposed. Because of the severity of the sanction the search intensity is so high that the share of workers with a benefit sanction reduces substantially, to $7 \%$. Now the ex ante effect causes an increase in search intensity of almost $30 \%$, while the ex post effect is about $2 \%$. Again this ex post effect is rather small compared to the effect found in micro-econometric research (see for example Abbring, Van den Berg and Van Ours (1997)). This does not have to do with the fact that in reality many of the unemployed workers that get a benefit sanction imposed have a high replacement rate $^{22}$. A more valid explanation for the difference between reality and simulations is that in reality unemployed workers underestimate the probability that they get a benefit sanction imposed. Therefore, in columns 6 and 7 of Table 2 we presents simulation results with a penalty of 0.5 but a smaller $\lambda$. Now, from column 6 it is clear that for $\lambda=0.1, s_{u}$ is lower than before, while $s_{p}$ has the same value. This implies that the ex ante effect is smaller and the ex post effect is larger. From column 7 it appears that for an even smaller $\lambda$ of 0.01 we find that $s_{u}$ is 0.72 , while $s_{p}$ is 0.93 . In other words, the ex ante effect is $1.4 \%$, while the ex post effect is almost $30 \%$. In this last simulation we find that hardly anyone gets a sanction imposed. As shown in lemma 2, we find a sizeable ex post effect only when $\lambda$ is small (compared to $\mu$ ), but then not many unemployed get penalized. The combination of a large ex post effect and a sizable fraction of unemployed with a benefit sanction could be caused by the misperception of the unemployed that $\lambda$ is small.

What is striking is that overall welfare in this system with benefit sanctions is higher than the welfare connected to the optimal replacement rate without benefit sanctions. Apparently, with a system of benefit sanctions welfare can be increased beyond the level where any change of replacement rate can bring the economy. From a mathematical point of view, this is not surprising. Because introducing a sanction system gives the government more instruments $(\lambda, \sigma$ and $p)$ beside the replacement rate $b$, one would expect a rise in welfare. What is interesting is the

\footnotetext{
${ }^{22}$ We performed a simulation starting from a replacement rate of 0.9 , which generates an unemployment rate of $20.8 \%$ and a search intensity of 0.44 . The introduction of a system of benefit sanctions with parameters $\lambda=0.5$ and $p=0.5$ lowers the unemployment rate to $11.3 \%$ ( $14 \%$ of the unemployed gets a benefit sanction imposed), but $s_{u}=0.90$ and $s_{p}=0.87$, so in this case we find a negative ex post effect while the ex ante effect is very large indeed.
} 
intuition the model provides for why sanctions can reduce unemployment more and yield higher welfare than reducing the replacement rate.

For instance, consider the following thought experiment. The government wants to raise welfare by stimulating search, but due to distributional (or other) considerations it does not want the unemployed to loose too much utility. In our comparisons of sanction systems with generic reductions in the replacement rate, it is the case that $V_{u}$ in the sanction system exceeds $V_{u}$ with the reduction in the replacement rate, while $V_{p}$ is smaller than $V_{u}$ with the replacement rate reduction. The point is that only a small fraction of the unemployed are actually sanctioned while all the unemployed suffer from a generic reduction in $b$. One way, albeit a crude one, to make these measures comparable in terms of how much the unemployed loose, is to consider the average value of being unemployed, $\bar{V} \equiv \frac{u_{u} V_{u}+u_{p} V_{p}}{u_{u}+u_{p}}$. Clearly, with a generic reduction in $b$ it is the case that $\bar{V}=V_{u}$. This average value of being unemployed with a sanction system is lower than in a system without benefit sanctions that has the same replacement rate of 0.7 (compare columns 5 and 1 in Table 2), but it hardly differs from the value of being unemployed with a replacement rate of 0.63 . In column 8 of Table 2 we show simulation results where we choose the level of the replacement rate equal to 0.643 , at which level the value of being unemployed is the same as $\bar{V}$ in the simulations of the fifth column. So, roughly speaking, on average the unemployed should be indifferent between a system with benefit sanctions that has the characteristics of the one in column 5 or a system that has no benefit sanctions but a lower replacement rate. It turns out that a system with benefit sanctions has higher overall welfare and lower unemployment than a system without benefit sanctions but a lower replacement rate. From this perspective a system with benefit sanctions is preferable. The intuition is again that the sanction system introduces a carrot in the form of the entitlement effect beside the stick of reducing the value of being unemployed. Because agents are risk averse, the stick is rather costly in terms of the welfare of the unemployed. Because a generic reduction in the replacement rate works only as a stick, the sanction system outperforms the reduction in $b$ in terms of welfare, search intensity and unemployment if both have the same effect on the average value of being unemployed. This is illustrated in Figure 5 where we show for the baseline model the relationship between welfare and $\sigma$. As shown welfare is decreasing in $\sigma$. Since, as argued above, the penalty system is equivalent to an across the board reduction in the replacement rate for $\sigma \longrightarrow+\infty$ it is clear that a penalty system with finite $\sigma$ is to be preferred above a generic reduction in the replacement rate. 


\subsection{The anatomy of benefit sanctions}

As indicated above we are not only interested in finding the overall effects of a benefit sanction system. We are also interested in the various components of the induced change in the labor market. In this section, we describe the way in which we can derive the various components. We start with the micro effects, that is the effects if none of the macro-variables change but only the direct effect on individuals' search behavior is accounted for ${ }^{23}$. To find the micro effects of a policy change, we keep $\theta, w$ and $\tau$ at their baseline value, and $V_{u}, s_{u}, V_{p}, s_{p}, u_{u}, u_{p}$ are endogenous. These variables are solved from the following equations

$$
\begin{aligned}
\rho V_{u} & =\frac{(b w)^{1-\zeta}}{1-\zeta}-\gamma\left(s_{u}\right)+\mu(\theta) s_{u}\left(V_{e}-V_{u}\right)+\lambda\left(\sigma-s_{u}\right)\left(V_{p}-V_{u}\right) \\
\gamma^{\prime}\left(s_{u}\right) & =\frac{\mu(\theta)}{\rho+\delta}\left(\frac{w^{1-\zeta}}{1-\zeta}-\rho V_{u}\right)+\lambda\left(V_{u}-V_{p}\right) \\
\rho V_{p} & =\frac{[(1-p) b w]^{1-\zeta}}{1-\zeta}-\gamma\left(s_{p}\right)+\mu(\theta) s_{p}\left(\frac{1}{\rho+\delta}\left(\frac{w^{1-\zeta}}{1-\zeta}+\delta V_{u}\right)-V_{p}\right) \\
\gamma^{\prime}\left(s_{p}\right) & =\mu(\theta)\left(\frac{1}{\rho+\delta}\left(\frac{w^{1-\zeta}}{1-\zeta}+\delta V_{u}\right)-V_{p}\right) \\
u_{u} & =\frac{\mu(\theta) s_{p} \delta}{\lambda \delta\left(\sigma-s_{u}\right)+\mu(\theta) s_{p}\left(\delta+\mu(\theta) s_{u}+\lambda\left(\sigma-s_{u}\right)\right)} \\
u_{p} & =\frac{\lambda \delta\left(\sigma-s_{u}\right)}{\lambda \delta\left(\sigma-s_{u}\right)+\mu(\theta) s_{p}\left(\delta+\mu(\theta) s_{u}+\lambda\left(\sigma-s_{u}\right)\right)}
\end{aligned}
$$

The difference between the solution to these equations and the base line values of $V_{u}, s_{u}, V_{p}, s_{p}, u_{u}, u_{p}$ is reported in column 1 of Tables 3 and 4 . These tables identify the different components of the introduction of a system of benefit sanctions. As shown, the micro effect is the main effect when it comes to the increase in search intensity. Similarly, the micro effect also has a large effect on the change in unemployment. As shown in Table 4 only the micro effect already reduces total unemployment with $1.5 \%$ points.

The crowding out effect is the effect that if more than one unemployed starts searching harder the net benefit for each individual is reduced, the unemployed crowd each other out. To find the crowding out effects we solve the same system of equations as under micro effects, except now we keep $v, w$ and $\tau$ at their baseline value and $\theta$ is endogenous. Hence we solve for the previous equations and

$$
\theta=\frac{v}{s_{u} u_{u}+s_{p} u_{p}}
$$

\footnotetext{
${ }^{23}$ In our nonlinear model the order in which the different components are derived may be important, but we think that the way we deal with the decomposition is a sensible one.
} 
As shown in Tables 3 and 4 the crowding out effect is not very important. The search intensity is hardly effected by the crowding out effect, but overall unemployment increases with $0.1 \%$ point.

To find the macro spillover effects we only keep $\tau$ at the baseline value. That is, $v$ is endogenous and $w$ is determined by (14). Now we get the effect that the sanction system reduces the value of being unemployed, and hence the wage rate because workers' fall back position deteriorates in the wage bargaining process. This reduction in $w$ reduces the benefits received by the unemployed because the replacement rates $\left(b\right.$ and $(1-p) b$, respectively) are fixed. Hence $V_{u}$ and $V_{p}$ fall in this 'macro spillover step'. This is partly offset by the rise in vacancies caused by the reduction in wages and hence rise in profits. Note that the macro spillover effects on search, tightness and unemployment are substantial. As indicated in Table 4 the vacancy rate increases $0.3 \%$, which causes the unemployment rate to go down with $1.1 \%$ point.

Finally, the tax effect is found as the difference between the model in which we keep $\tau$ fixed and the model where $\tau$ (and all other endogenous variables) varies to satisfy the government budget constraint (15). The tax effect does not turn out to be very important. This may not seem very noteworthy but it is from the perspective of the monitoring costs of a system of benefit sanctions. From Table 4 for example it is clear that the reduction of the tax rate of 0.02 hardly affects the outcome of the model with respect to unemployment rates or search intensities. This means that a system of benefit sanctions with the characteristics as indicated in Table 4 could be financed by the decline in tax rate, which is about $1.8 \%$ of the total value of production. This should be sufficient to set up a decent monitoring system ${ }^{24}$.

All in all, the decomposition of the effects of the introduction of a benefit sanction system shows that it is the micro effect and the macro spillover effects that are the main components causing the changes in search intensity, unemployment and labor market tightness. Thus the effects found in the micro studies, cited in section 2, are an important first step in evaluating a sanction system but the macro effects should not be neglected. In terms of search intensity, unemployment and labor market tightness the micro studies underestimate the beneficial effects of introducing sanctions.

\footnotetext{
${ }^{24} \mathrm{An}$ example may make this clear. In the Netherlands there are 6 million employed workers. If $1.8 \%$ of the value of the production could be used for a monitoring system, then at the average wage one could finance about 100,000 monitoring workers. Suppose that the unemployment rate is about $10 \%$, then there would be 650,000 unemployed workers. If each monitoring worker would look after 20 unemployed ( 2 hours per week for every unemployed), then one would only need 33,000 workers, which is substantially less than is available from the tax reduction.
} 


\section{Conclusions}

Unemployment is high in many countries that have reasonably generous benefits with very long periods of entitlement. However, it is not this characteristic in itself that is important. What matters is that there are active policies to monitor abuse of benefits and to push unemployed back into work. In this respect a system of benefit sanctions could be very important. If unemployed workers do not comply with eligibility criteria guidelines, they may face a reduction of their unemployment benefits, that is they should get a benefit sanction. Benefit sanctions are imposed mainly for two reasons. The first reason is psychological. Workers that do not obey administrative rules should face a penalty. The second and most important reason is that penalties affect the search behavior of unemployed (even before they are actually sanctioned). Since penalties make unemployment less attractive and introduce an entitlement effect, workers increase their search intensity thereby increasing their job finding rate and reducing unemployment duration.

From micro-studies there is evidence about the effects of benefit sanctions on the search behavior of unemployed workers. From these studies it appears that benefit sanctions substantially increase the transition from unemployment to work. However, in micro-studies it is not possible to investigate the effect of a system of benefit sanctions per se, since it is not possible to study the behavior of unemployed in the absence of such a system. Furthermore, in micro studies it is not possible to investigate the effect of an increase in sanction rate or penalty. It is also not possible to investigate possible crowding effects induced by the system or the way the increased search intensity of the unemployed affects the vacancy creation by employers. To study these types of effects one needs a macro-model. In this paper we present a macro-model of the labor market which enables us to perform a more detailed analysis of the way benefit sanctions affect unemployment.

In our model we assume that unemployed behave rationally. Conditional on the unemployment benefits, the sanction rate, the wage when employed and the time preference, unemployed choose an optimal level of search intensity. There is an ex ante and an ex post effect of benefit sanctions. The ex ante effect refers to the optimal search intensity of workers, which is higher than it would be if workers would not face the possibility of getting a sanction imposed. The ex post effect refers to the effect on search of having lower benefits once a sanction is imposed. In the labor market of our model, we assume that wages are determined by negotiations between workers and employers. Vacancies are created under the 
assumption of free entry, that is until the value for the firm of posting a vacancy equals zero. The flows from unemployment to employment are determined by a matching process in the labor market.

In our simulations we start with parameter values that are in line with the Dutch labor market of the early 1990s. Then, we investigate to what extent labor market indicators change as benefits are reduced or a system of benefit sanctions is introduced. We find that a lowering of the replacement rate lowers the unemployment rate. However, we also show that a system of benefit sanctions can increase welfare beyond the level where any change of replacement rate can bring the economy. The ex ante effect turns out to be at least as important as the ex post effect. The split-up between the two depends to a large extent on the parameters of the sanction process. With a low value of the sanction parameter the possibility of getting a sanction imposed is small and the search of the unemployed will not be affected very much. The main effect is after the sanction is imposed. So, in this case the ex post effect dominates. With a high value of the sanction parameter the unemployed will try to reduce the sanction rate by increasing their search intensity. Then, the main effect is the ex ante effect. It is even possible that the ex post effect is very small, which in micro research could lead to the erroneous conclusion that sanctions do not have an effect. Nevertheless they do but the main effect is in the threat of a penalty, not because a penalty is imposed. Furthermore, we find that the micro effect and the macro spillover effects are the two main components causing the changes in unemployment. The crowding out effect and the tax effects are rather small. This last observation also implies that from the reduction in tax rate that goes with the system of benefit sanctions it is possible to finance the monitoring costs without this having a big counterbalancing effect.

All in all, we advocate that when financial incentives for unemployed are to be increased the introduction of a system of sanctions is a good alternative for a reduction of the level of benefits. 
Table 1 Sanctions, benefits and unemployment in OECD countries

\begin{tabular}{|l|c|c|c|}
\hline & Sanction rate $^{a)}$ & Replacement rate $^{b)}$ & Unemployment rate $^{c)}$ \\
\hline Belgium & 4.2 & 51 & 8.8 \\
\hline Denmark & 4.3 & 71 & 5.1 \\
\hline Finland & 10.3 & 65 & 11.4 \\
\hline Germany & 1.1 & 35 & 7.8 \\
\hline Netherlands & 36.0 & 70 & 4.0 \\
\hline Sweden & 0.2 & 76 & 8.2 \\
\hline Switzerland & 38.5 & 70 & 3.8 \\
\hline UK & 10.3 & 18 & 6.3 \\
\hline US & 25.7 & 27 & 4.5 \\
\hline
\end{tabular}

a) Sanctions during benefit periods as a percentage of the average stock of benefit claims, 1997-1998. Source: Grubb (1999), except for Sweden (Swedish Labor Market Board) and Netherlands (authors' calculations)

b)

Gross replacement rates: benefit entitlement before tax as a percentage of previous earnings before tax, single workers in the first year of their unemployment spell, 1995 (except US 1994); source: Martin (1996)

c) OECD standardized unemployment rate, 1998

Table 2 Simulation results

\begin{tabular}{|l|l|l|l|l|l|l|l|l|}
\hline & $(1)$ & $(2)$ & $(3)$ & $(4)$ & $(5)$ & $(6)$ & $(7)$ & $(8)$ \\
\hline $\mathbf{R R}^{a)}$ & 0.7 & 0.8 & 0.63 & 0.7 & 0.7 & 0.7 & 0.7 & 0.643 \\
\hline $\mathbf{p}^{a)}$ & 0.0 & 0.0 & 0.0 & 0.1 & 0.5 & 0.5 & 0.5 & 0.0 \\
\hline $\boldsymbol{\lambda}^{a)}$ & 0.0 & 0.0 & 0.0 & 0.5 & 0.5 & 0.1 & 0.01 & 0.0 \\
\hline$s_{u}$ & 0.71 & 0.60 & 0.77 & 0.76 & 0.91 & 0.80 & 0.72 & 0.76 \\
\hline$s_{p}$ & & & & 0.77 & 0.93 & 0.93 & 0.93 & \\
\hline$V_{u}$ & 3.49 & 3.37 & 3.45 & 3.53 & 3.50 & 3.53 & 3.50 & 3.46 \\
\hline$V_{p}$ & & & & 3.45 & 2.89 & 2.82 & 2.73 & \\
\hline $\bar{V}^{b)}$ & 3.49 & 3.37 & 3.45 & 3.51 & 3.46 & 3.51 & 3.50 & 3.46 \\
\hline$u_{u}$ & & & & 6.36 & 5.83 & 7.24 & 8.49 & \\
\hline$u_{p}$ & & & & 1.61 & 0.44 & 0.26 & 0.00 & \\
\hline$u$ & 8.73 & 12.1 & 7.31 & 7.97 & 6.27 & 7.50 & 8.49 & 7.54 \\
\hline$\theta$ & 0.34 & 0.23 & 0.43 & 0.36 & 0.43 & 0.38 & 0.38 & 0.42 \\
\hline$v$ & 2.14 & 1.69 & 2.44 & 2.22 & 2.46 & 2.28 & 2.16 & 2.39 \\
\hline$w$ & 0.87 & 0.84 & 0.87 & 0.87 & 0.88 & 0.87 & 0.87 & 0.87 \\
\hline$\tau$ & 0.07 & 0.11 & 0.05 & 0.06 & 0.05 & 0.06 & 0.07 & 0.05 \\
\hline$W$ & 3.10 & 2.84 & 3.13 & 3.15 & 3.19 & 3.17 & 3.11 & 3.13 \\
\hline
\end{tabular}

a) parameter values; other baseline parameter values see text

b) $\bar{V}_{\text {is defined as }} \bar{V} \equiv \frac{u_{u} V_{u}+u_{p} V_{p}}{u_{u}+u_{p}}$ 
Table 3 Decomposition of the effects when a system of benefit sanctions is introduced; $\lambda=0.5$ and $\mathbf{p}=\mathbf{0 . 1 0}$

\begin{tabular}{|l|r|r|r|r|r|}
\hline & micro & crowding & spillover & tax & total \\
\hline$s_{u}$ & 0.04 & 0.00 & 0.02 & -0.00 & 0.05 \\
\hline$s_{p}$ & 0.04 & -0.00 & 0.02 & -0.00 & 0.06 \\
\hline$V_{u}$ & -0.04 & -0.01 & -0.01 & 0.09 & 0.03 \\
\hline$V_{p}$ & -0.09 & -0.00 & -0.04 & 0.09 & -0.04 \\
\hline$u_{u}$ & -2.24 & 0.02 & -0.15 & 0.00 & -2.37 \\
\hline$u_{p}$ & 1.83 & 0.02 & -0.25 & 0.01 & 1.61 \\
\hline$u$ & -0.41 & 0.04 & -0.40 & 0.01 & -0.76 \\
\hline$\theta$ & 0 & -0.00 & 0.02 & 0.00 & 0.02 \\
\hline$v$ & 0 & 0 & 0.08 & 0.00 & 0.08 \\
\hline$w$ & 0 & 0 & -0.00 & 0.01 & 0.00 \\
\hline$\tau$ & 0 & 0 & 0 & -0.01 & -0.01 \\
\hline
\end{tabular}

Table 4 Decomposition of the effects when a system of benefit sanctions is introduced; $\lambda=0.5$ and $\mathbf{p}=\mathbf{0 . 5 0}$

\begin{tabular}{|l|r|r|r|r|r|}
\hline & micro & crowding & spillover & tax & total \\
\hline$s_{u}$ & 0.16 & 0.00 & 0.04 & -0.00 & 0.20 \\
\hline$s_{p}$ & 0.17 & -0.00 & 0.05 & -0.00 & 0.21 \\
\hline$V_{u}$ & -0.17 & -0.02 & -0.05 & 0.25 & 0.01 \\
\hline$V_{p}$ & -0.54 & -0.02 & -0.30 & 0.26 & -0.60 \\
\hline$u_{u}$ & -2.28 & 0.08 & -0.68 & -0.02 & -2.90 \\
\hline$u_{p}$ & 0.82 & 0.02 & -0.41 & 0.01 & 0.44 \\
\hline$u$ & -1.46 & 0.10 & -1.09 & -0.01 & -2.46 \\
\hline$\theta$ & 0 & -0.01 & 0.10 & 0.00 & 0.09 \\
\hline$v$ & 0 & 0 & 0.31 & 0.01 & 0.32 \\
\hline$w$ & 0 & 0 & -0.01 & 0.02 & 0.01 \\
\hline$\tau$ & 0 & 0 & 0 & -0.02 & -0.02 \\
\hline
\end{tabular}




\section{References}

Abbring, J.H., G.J. van den Berg and J.C. van Ours (1997) The effect of unemployment insurance sanctions on the transition rate from unemployment to employment, Working Paper, Tinbergen Institute, Amsterdam.

Ashenfelter, O., D. Ashmore and O. Deschênes (1999) Do unemployment insurance recipients actively seek work? Randomized trials in four U.S. states, NBER working paper 6982.

Atkinson, A.B. and J. Micklewright (1991) Unemployment Compensation and Labor Market Transitions: A Critical Review, Journal of Economic Literature, 29,1679-1727.

Becker, G.S. (1968) Crime and punishment: an economic approach, Journal of Political Economy, 76, 169-217.

Bean, C.R. (1994) European unemployment: a survey, Journal of Economic Literature 32, 573-619.

Björklund, A. and B. Holmlund (1991) The economics of unemployment insurance: the case of Sweden, in: A. Björklund, R. Haveman, R. Hollister and B. Holmlund (eds.) Labour market policy and unemployment insurance, Oxford, Clarendon Press.

Black, D.A., M.C. Berger, B.J. Noel and J.A. Smith (1998) Is the threat of training more effective than training itself? Experimental evidence from UI claimant profiling, mimeo.

Boone, J. and L. Bovenberg (1999) Optimal tax policy in search models, mimeo Tilburg University.

Broersma, L. and J.C. van Ours (1999) Job searchers, job matches and the elasticity of matching, Labour Economics, 6, 77-93.

Burgess, P.L. (1992) Compliance with unemployment-insurance job-search regulations, Journal of Law and Economics, 35, 371-396.

Cahuc, P. and E. Lehmann (1997) Equilibrium unemployment and the time sequence of unemployment benefits, Working Paper, Université de Paris.

Calmfors, L. (1994), Active labor market policy and unemployment - a framework for the analysis of crucial design features, OECD Economic Studies, $22(1), 7-47$. 
Davidson, C. and S. Woodbury (1993), The displacement effect of reemployment bonus programs, Journal of Labor Economics, 11, 575-605.

Davidson, C. and S. Woodbury (1995), Wage subsidies for dislocated workers, unpublished manuscript, W.E. Upjohn Institute for Employment Research, Kalamazoo, MI

Davidson, C. and S. Woodbury (1997) Optimal unemployment insurance, Journal of Public Economics, 64, 359-387.

Devine, T.J. and N.M. Kiefer (1991) Empirical Labor Economics: The Search Approach, Oxford University Press, Oxford.

Devine, T.J. and N.M. Kiefer (1993), The Empirical Status of Job Search Theory, Labour Economics, 1, 3-24.

Dolton, P. and D. O'Neill (1996), Unemployment duration and the restart effect: some experimental evidence, The Economic Journal, 106, 387-400.

Dolton, P. and D. O'Neill (1996) The Restart effect and the return to full-time stable employment, Journal of the Royal Statistical Society Series A, 19, 275-288.

Fredriksson, P. and B. Holmlund (1998) Optimal unemployment insurance in search equilibrium, Working Paper, Department of Economics, Uppsala University.

Gorter, C. and G.R.J. Kalb (1996) Estimating the effect of counseling and monitoring the unemployed using a job search model, Journal of Human Resources 31, 590-610.

Grubb, D. (1999) Making work pay: the role of eligibility criteria for unemployment benefits, mimeo, Paris, OECD.

Heckman, J.J., L. Lochner and C. Taber (1998) General equilibrium treatment effect: A study of tuition policy, American Economic Review, 88, 381-386.

Holmlund, B. (1997) Unemployment insurance in theory and practice, Working Paper, Department of Economics, Uppsala University.

Hopenhayn, H.A. and J.P. Nicolini (1997) Optimal unemployment insurance, Journal of Political Economy, 105, 412-438. 
Hosios, J.J. (1990) On the efficiency of matching and related models of search and unemployment, Review of Economic Studies, 57, 279-298.

Layard, R., S. Nickell and R. Jackman (1991) Unemployment: Macroeconomic Performance on the Labour Market, Oxford University Press, Oxford.

Ljungqvist, L. and Th.J. Sargent (1995) The Swedish unemployment experience, European Economic Review, 39, 1043-1070.

Ljungqvist, L. and Th.J. Sargent (1998) The European unemployment dilemma, Journal of Political Economy, 106, 514-550.

Martin, J.P. (1996) Measures of replacement rates for the purpose of international comparisons: a note, OECD Economic Studies, 26, 99-115.

Meyer, B.D. (1995) Lessons from the U.S. unemployment insurance experiments, Journal of Economic Literature, 33, 91-131.

Mortensen, D.T. (1977) Unemployment insurance and job search decisions, Industrial and Labor Relations Review, 30, 505-517.

Mortensen, D.T. and C.A. Pissarides (1999) New developments in models of search in the labor market, in O. Ashenfelter and D. Card (eds.), Handbook of Labor Economics, Volume 3, North-Holland, Amsterdam.

Nickell, S.J. (1997) Unemployment and labor market rigidities: Europe versus North America, Journal of Economic Perspectives, 11, 55-74.

Nickell, S.J. and J.C. van Ours (1999) Why has unemployment in The Netherlands and the United Kingdom fallen so much?, Canadian Public Policy, forthcoming.

Nickell, S.J. and J.C. van Ours (2000) The Netherlands and the United Kingdom: a European unemployment miracle?, Economic Policy, forthcoming.

Shavell, S. and L. Weiss (1979) The optimal payment of unemployment insurance benefits over time, Journal of Political Economy, 87, 1347-1363.

Van den Berg, G.J., B. van der Klaauw and J.C. van Ours (1998) Punitive sanctions and the transition rate from welfare to work, Discussion Paper, CentER for Economic Research, Tilburg. 
Van den Berg, G.J. and B. van der Klaauw (1999) Evaluating the effect of counseling and monitoring on the transition rate from unemployment to work, using data from a social experiment, mimeo, Amsterdam, Tinbergen Institute.

Van Ours, J.C. (1991) The efficiency of the Dutch labor market in matching unemployment and vacancies, De Economist, 139, 358-378.

Yaniv, G. (1997) Welfare fraud and welfare stigma, Journal of Economic Psychology, 18, 435-451. 


\section{Appendix: Proofs of results}

This appendix contains the proofs of the results in the main text.

Proof of lemma 1. By choosing $s=0$ in equation (7), one finds $\rho V_{p} \geq$ $\frac{[(1-p) b w]^{1-\zeta}}{1-\zeta}$. Further, by the properties of $\gamma(s)$ and the result below that $V_{e}>V_{p}$ one finds $\rho V_{p}>\frac{[(1-p) b w]^{1-\zeta}}{1-\zeta}$.

The inequality in the middle, $V_{u}>V_{p}$, can be proved by contradiction as follows. Suppose not, that is suppose $V_{u} \leq V_{p}$, then one finds

$$
\begin{aligned}
\rho V_{u} & =\frac{(b w)^{1-\zeta}}{1-\zeta}-\gamma\left(s_{u}\right)+\mu s_{u}\left(V_{e}-V_{u}\right)+\lambda\left(\sigma-s_{u}\right)\left(V_{p}-V_{u}\right) \\
& \geq \frac{(b w)^{1-\zeta}}{1-\zeta}-\gamma\left(s_{p}\right)+\mu s_{p}\left(V_{e}-V_{u}\right)+\lambda\left(\sigma-s_{p}\right)\left(V_{p}-V_{u}\right) \\
& >\frac{[(1-p) b w]^{1-\zeta}}{1-\zeta}-\gamma\left(s_{p}\right)+\mu s_{p}\left(V_{e}-V_{p}\right)=\rho V_{p}
\end{aligned}
$$

where the first inequality follows from the fact that $s_{p}$ is not necessarily the optimal choice of search intensity for an unemployed person without a penalty; the second inequality follows from $p>0$ and the initial assumption $V_{u} \leq V_{p}$. This set of inequalities contradicts the initial assumption $V_{u} \leq V_{p}$. Hence $V_{u}>V_{p}$.

The first inequality $V_{e}>V_{u}$ follows from equation (8) with $0<\beta<1$. QED

Proof of lemma 2. Rewrite equation (6) as

$$
\rho V_{u}=\frac{(b w)^{1-\zeta}}{1-\zeta}+\lambda \sigma\left(V_{p}-V_{u}\right)+\max _{0 \leq s \leq 1}\left\{-\gamma(s)+\mu s\left(V_{e}-V_{p}\right)+(\lambda-\mu) s\left(V_{u}-V_{p}\right)\right\}
$$

Then using the result derived above that $V_{u}>V_{p}$ and comparing this equation with equation (7) yields that $s_{p} \lesseqgtr s_{u}$ depending on whether $\lambda \gtreqless \mu$. QED

Proof of lemma 3. First, rewrite equations (6) and (7), using equation (8) as

$$
\begin{aligned}
& \rho V_{u}=\frac{(b w)^{1-\zeta}}{1-\zeta}+\max _{0 \leq s \leq 1}\left\{-\gamma(s)+\mu s \frac{1-\beta}{\beta} \frac{w^{-\zeta}}{1+\tau} \frac{\theta c}{\mu}-\lambda(\sigma-s)\left(V_{u}-V_{p}\right)\right\} \\
& \rho V_{p}=\frac{[(1-p) b w]^{1-\zeta}}{1-\zeta}+\max _{0 \leq s \leq 1}\left\{-\gamma(s)+\mu s \frac{1-\beta}{\beta} \frac{w^{-\zeta}}{1+\tau} \frac{\theta c}{\mu}+\mu s\left(V_{u}-V_{p}\right)\right\}
\end{aligned}
$$

Then substituting $\rho V_{u}$ from equation (5), $x \equiv V_{u}-V_{p}$, adding $\rho V_{u}$ on both sides of the last equation and bringing $\rho V_{p}$ to the right hand side, yields equations (9) and (10).

The following three observations guarantee that an equilibrium exists and that it is unique. First, equation (9) is downward sloping in $(x, w)$ space. Second, equation (10) is upward sloping in $(x, w)$ space. Finally, since at $x=0$ equation 
(9) has a higher intercept than equation (10), it follows from these observations that an equilibrium $(\hat{x}, \hat{w})$ exists and that it is unique. QED

Proof of lemma 4. To find the effects of $p$ we differentiate equations (9) and (10) with respect to $w, x$ and $p$ :

$$
A\left(\begin{array}{c}
d w \\
d x
\end{array}\right)=\left(\begin{array}{c}
0 \\
-(1-p)^{-\zeta}(w b)^{1-\zeta} d p
\end{array}\right)
$$

where

$$
A=\left(\begin{array}{cc}
\Xi_{u} & \lambda\left(\sigma-s_{u}\right) \\
\Xi_{p} & -\left(\rho+s_{p} \mu\right)
\end{array}\right)
$$

with

$$
\begin{aligned}
& \Xi_{u} \equiv\left(1-b^{1-\zeta}\right) w^{-\zeta}+\zeta \frac{1-\beta}{\beta} \frac{w^{-(1+\zeta)}}{1+\tau}(\rho+\delta) \frac{c \theta}{\mu}+\zeta s_{u} \frac{1-\beta}{\beta} \frac{w^{-(1+\zeta)}}{1+\tau} c \theta \\
& \Xi_{p} \equiv\left(1-((1-p) b)^{1-\zeta}\right) w^{-\zeta}+\zeta \frac{1-\beta}{\beta} \frac{w^{-(1+\zeta)}}{1+\tau}(\rho+\delta) \frac{c \theta}{\mu}+\zeta s_{p} \frac{1-\beta}{\beta} \frac{w^{-(1+\zeta)}}{1+\tau} c \theta
\end{aligned}
$$

Consequently we find

$$
\left(\begin{array}{c}
\frac{d w}{d p} \\
\frac{d x}{d p}
\end{array}\right)=A^{-1}\left(\begin{array}{c}
0 \\
-(1-p)^{-\zeta}(w b)^{1-\zeta}
\end{array}\right)
$$

where

$$
A^{-1}=\frac{1}{\Delta}\left(\begin{array}{cc}
\left(\rho+s_{p} \mu\right) & \lambda\left(\sigma-s_{u}\right) \\
\Xi_{p} & -\Xi_{u}
\end{array}\right)
$$

with $\Delta$ equal to minus the determinant of the matrix $A$,

$$
\Delta \equiv\left(\rho+s_{p} \mu\right) \Xi_{u}+\Xi_{p} \lambda\left(\sigma-s_{u}\right)>0
$$

It follows that $\frac{d w}{d p}<0, \frac{d x}{d p}>0$ and hence $\frac{d s_{u}}{d p}>0, \frac{d s_{p}}{d p}>0$. Where the last two inequalities follow from differentiating equations (11) and (12) with respect to $p$.

The effects of $\lambda$ are found in a similar way:

$$
\left(\begin{array}{c}
\frac{d w}{d \lambda} \\
\frac{d x}{d \lambda}
\end{array}\right)=A^{-1}\left(\begin{array}{c}
-\left(\sigma-s_{u}\right) x \\
0
\end{array}\right)
$$

consequently $\frac{d w}{d \lambda}=\frac{-\left(\rho+\mu s_{p}\right)\left(\sigma-s_{u}\right) x}{\Delta}<0, \frac{d x}{d \lambda}=\frac{-\Xi_{p}\left(\sigma-s_{u}\right) x}{\Delta}<0$. In order to determine $\frac{d s_{u}}{d \lambda}$ we write

$$
\gamma^{\prime \prime}\left(s_{u}\right) \frac{d s_{u}}{d \lambda}=-\zeta \frac{1-\beta}{\beta} \frac{w^{-(1+\zeta)}}{1+\tau} c \theta \frac{d w}{d \lambda}+x+\lambda \frac{d x}{d \lambda}>0
$$


because $\frac{d w}{d \lambda}<0$ and one can verify that $x+\lambda \frac{d x}{d \lambda}>0$. Hence $\frac{d s_{u}}{d \lambda}>0$ because $\gamma^{\prime \prime}(s)>0$. In order to determine $\frac{d s_{p}}{d \lambda}$, we write

$$
\begin{aligned}
\gamma^{\prime \prime}\left(s_{p}\right) \frac{d s_{p}}{d \lambda} & =-\zeta \frac{1-\beta}{\beta} \frac{w^{-(1+\zeta)}}{1+\tau} c \theta \frac{d w}{d \lambda}+\mu \frac{d x}{d \lambda} \\
& =\frac{-\left(\sigma-s_{u}\right) x \mu\left[\left(1-((1-p) b)^{1-\zeta}\right) w^{-\zeta}+\zeta \delta \frac{1-\beta}{\beta} \frac{w^{-(1+\zeta)}}{1+\tau} \frac{c \theta}{\mu}\right]}{\Delta}<0
\end{aligned}
$$

Hence $\frac{d s_{p}}{d \lambda}<0$.

To determine the effects of $b$, we write

$$
\left(\begin{array}{c}
\frac{d w}{d b} \\
\frac{d x}{d b}
\end{array}\right)=A^{-1}\left(\begin{array}{c}
b^{-\zeta} w^{1-\zeta} \\
(1-p)^{1-\zeta} b^{-\zeta} w^{1-\zeta}
\end{array}\right)
$$

Hence

$$
\begin{aligned}
\frac{d w}{d b}= & \frac{b^{-\zeta} w^{1-\zeta}\left(\left(\rho+\mu s_{p}\right)+\lambda\left(\sigma-s_{u}\right)(1-p)^{1-\zeta}\right)}{\Delta}>0 \\
\frac{d x}{d b}= & \frac{b^{-\zeta} w^{1-\zeta}\left(\Xi_{p}-(1-p)^{1-\zeta} \Xi_{u}\right)}{\Delta} \\
= & \frac{b^{-\zeta} w^{1-\zeta}\left(1-(1-p)^{1-\zeta}\right)}{\Delta}\left(w^{-\zeta}+\zeta \frac{1-\beta}{\beta} \frac{w^{-(1+\zeta)}}{1+\tau}(\rho+\delta) \frac{c \theta}{\mu}\right)+ \\
& +\frac{b^{-\zeta} w^{1-\zeta}\left(s_{p}-(1-p)^{1-\zeta} s_{u}\right)}{\Delta} \zeta \frac{1-\beta}{\beta} \frac{w^{-(1+\zeta)}}{1+\tau} c \theta
\end{aligned}
$$

Consequently

$$
\begin{aligned}
\gamma^{\prime \prime}\left(s_{u}\right) \frac{d s_{u}}{d b}= & -\zeta \frac{1-\beta}{\beta} \frac{w^{-(1+\zeta)}}{1+\tau} c \theta \frac{d w}{d b}+\lambda \frac{d x}{d b} \\
= & \frac{b^{-\zeta} w^{1-\zeta}}{\Delta}\left(-\zeta \frac{1-\beta}{\beta} \frac{w^{-(1+\zeta)}}{1+\tau} c \theta\left[\mu s_{p}+\lambda\left(\sigma-s_{p}\right)+\rho\right.\right. \\
& \left.\left.-\lambda \frac{\rho+\delta+\sigma \mu}{\mu}\left(1-(1-p)^{1-\zeta}\right)\right]+\lambda\left(1-(1-p)^{1-\zeta}\right) w^{-\zeta}\right) \\
& \left\{\begin{array}{lll}
>0 & \text { if } \zeta=0 \\
<0 & \text { if } & p=0
\end{array}\right.
\end{aligned}
$$

Similarly,

$$
\begin{aligned}
\gamma^{\prime \prime}\left(s_{p}\right) \frac{d s_{p}}{d b} & =-\zeta \frac{1-\beta}{\beta} \frac{w^{-(1+\zeta)}}{1+\tau} c \theta \frac{d w}{d b}+\mu \frac{d x}{d b} \\
& =\frac{b^{-\zeta} w^{1-\zeta}}{\Delta}\left(-\zeta \frac{1-\beta}{\beta} \frac{w^{-(1+\zeta)}}{1+\tau} c \theta(1-p)^{1-\zeta}\left[\mu s_{u}+\lambda\left(\sigma-s_{u}\right)\right]+\right.
\end{aligned}
$$




$$
\begin{aligned}
& +\mu\left(1-(1-p)^{1-\zeta}\right) w^{-\zeta}-\zeta(1-p)^{1-\zeta} \frac{1-\beta}{\beta} \frac{w^{-(1+\zeta)}}{1+\tau}(\rho+\delta) c \theta+ \\
& \left.+\zeta \frac{1-\beta}{\beta} \frac{w^{-(1+\zeta)}}{1+\tau} \delta c \theta\right) \\
& \left\{\begin{array}{l}
>0 \text { if } \zeta=0 \\
<0 \text { if } p=0
\end{array}\right.
\end{aligned}
$$

To determine the effects of $\sigma$, we write

$$
\left(\begin{array}{c}
\frac{d w}{d \sigma} \\
\frac{d x}{d \sigma}
\end{array}\right)=A^{-1}\left(\begin{array}{c}
-\lambda x \\
0
\end{array}\right)
$$

Hence

$$
\begin{aligned}
& \frac{d w}{d \sigma}=\frac{-\left(\rho+\mu s_{p}\right) \lambda x}{\Delta}<0 \\
& \frac{d x}{d \sigma}=\frac{-\Xi_{p} \lambda x}{\Delta}<0
\end{aligned}
$$

Consequently,

$$
\begin{aligned}
\gamma^{\prime \prime}\left(s_{u}\right) \frac{d s_{u}}{d \sigma}= & \zeta \frac{1-\beta}{\beta} \frac{w^{-(1+\zeta)}}{1+\tau} c \theta \frac{\left(\rho+\mu s_{p}\right) \lambda x}{\Delta}-\lambda \frac{\Xi_{p} \lambda x}{\Delta} \\
= & \frac{\lambda x}{\Delta}\left(\zeta \frac{1-\beta}{\beta} \frac{w^{-(1+\zeta)}}{1+\tau} c \theta\left(\rho\left(1-\frac{\lambda}{\mu}\right)+s_{p}(\mu-\lambda)-\frac{\lambda}{\mu} \delta\right)\right. \\
& \left.-\lambda\left(1-((1-p) b)^{1-\zeta}\right) w^{-\zeta}\right) \\
< & 0 \text { if } \zeta=0
\end{aligned}
$$

Similarly,

$$
\begin{aligned}
\gamma^{\prime \prime}\left(s_{p}\right) \frac{d s_{p}}{d \sigma} & =\zeta \frac{1-\beta}{\beta} \frac{w^{-(1+\zeta)}}{1+\tau} c \theta \frac{\left(\rho+\mu s_{p}\right) \lambda x}{\Delta}-\mu \frac{\Xi_{p} \lambda x}{\Delta} \\
& =-\frac{\lambda x}{\Delta}\left(\mu\left(1-((1-p) b)^{1-\zeta}\right) w^{-\zeta}+\zeta \delta \frac{1-\beta}{\beta} \frac{w^{-(1+\zeta)}}{1+\tau} c \theta\right)<0
\end{aligned}
$$

To determine the effects of $\theta$, we write

$$
\left.\left(\begin{array}{c}
\frac{d w}{d \theta} \\
\frac{d x}{d \theta}
\end{array}\right)=A^{-1}\left(\begin{array}{c}
\frac{1-\beta}{\beta} \frac{w^{-\zeta}}{1+\tau} c\left(\frac{\rho+\delta}{\mu}(1-\eta)+s_{u}\right. \\
\frac{1-\beta}{\beta} \frac{w^{-\zeta}}{1+\tau} c\left(\frac{\rho+\delta}{\mu}(1-\eta)+s_{p}\right.
\end{array}\right)\right)
$$

Hence

$$
\frac{d w}{d \theta}=\frac{\frac{1-\beta}{\beta} \frac{w^{-\zeta}}{1+\tau} c\left[\frac{\rho+\delta}{\mu}(1-\eta)\left(\rho+\mu s_{p}+\lambda\left(\sigma-s_{u}\right)\right)+\rho s_{u}+\mu s_{p} s_{u}+\lambda s_{p}\left(\sigma-s_{u}\right)\right]}{\Delta}>0
$$




$$
\begin{aligned}
\frac{d x}{d \theta}= & \frac{\frac{1-\beta}{\beta} \frac{w^{-\zeta}}{1+\tau} c}{\Delta}\left(\frac{\rho+\delta}{\mu}(1-\eta)\left(\Xi_{p}-\Xi_{u}\right)+s_{u} \Xi_{p}-s_{p} \Xi_{u}\right) \\
= & \frac{\frac{1-\beta}{\beta} \frac{w^{-\zeta}}{1+\tau} c}{\Delta}\left((p b)^{1-\zeta} w^{-\zeta}\left(s_{u}+\frac{\rho+\delta}{\mu}(1-\eta)\right)-\left(s_{p}-s_{u}\right) \times\right. \\
& \left.\times\left[\eta \zeta \frac{1-\beta}{\beta} \frac{w^{-(1+\zeta)}}{1+\tau} \frac{c \theta}{\mu}(\rho+\delta)+\left(1-b^{1-\zeta}\right) w^{-\zeta}\right]\right)
\end{aligned}
$$

Using these two expressions, we derive

$$
\begin{aligned}
\gamma^{\prime \prime}\left(s_{u}\right) \frac{d s_{u}}{d \theta}= & \frac{1-\beta}{\beta} \frac{w^{-\zeta}}{1+\tau} c-\zeta \frac{1-\beta}{\beta} \frac{w^{-(1+\zeta)}}{1+\tau} c \theta \frac{d w}{d \theta}+\lambda \frac{d x}{d \theta} \\
= & \frac{\frac{1-\beta}{\beta} \frac{w^{-\zeta}}{1+\tau} c}{\Delta}\left(\rho \Xi_{u}+s_{p} \Xi_{u}(\mu-\lambda)+\lambda \sigma \Xi_{p}-\zeta \frac{1-\beta}{\beta} \frac{w^{-(1+\zeta)}}{1+\tau} c \theta \times\right. \\
& \times\left[\frac{\rho+\delta}{\mu}(1-\eta)\left(\lambda\left(\sigma-s_{p}\right)+\rho+\mu s_{p}\right)+\rho s_{u}+(\mu-\lambda) s_{u} s_{p}+\lambda \sigma s_{p}\right]+ \\
& \left.\lambda \frac{\rho+\delta}{\mu}(1-\eta)(p b)^{1-\zeta} w^{-\zeta}\right) \\
= & \frac{1-\beta}{\beta} \frac{w^{-\zeta}}{\Delta} c \\
& \lambda \sigma\left(1-((1-p) b)^{1-\zeta}\right) w^{-\zeta}+\zeta \eta \frac{1-\beta}{\beta} \frac{w^{-(1+\zeta)}}{1+\tau} c \theta \frac{\rho+\delta}{\mu}\left((\mu-\lambda) s_{p}+\rho+\lambda \sigma\right) \\
& \left.+\lambda \frac{\rho+\delta}{\mu}(1-\eta)(p b)^{1-\zeta} w^{-\zeta}\right) \\
& \frac{1-\beta}{\beta} \frac{w^{-\zeta}}{1+\tau} c \\
\Delta & +\lambda\left(1-b^{1-\zeta}\right) w^{-\zeta}+\mu s_{p}\left(1-b^{1-\zeta}\right) w^{-\zeta}+\lambda\left(\sigma-s_{p}\right)\left(1-b^{1-\zeta}\right) w^{-\zeta}+ \\
& \left.\times\left(\mu w_{p}+\rho+\lambda\left(\sigma-s_{p}\right)\right)+\lambda \frac{\rho+\delta}{\mu}(1-\eta)(p b)^{1-\zeta} w^{-\zeta}\right) \\
> & 0
\end{aligned}
$$

Similarly

$$
\begin{aligned}
\gamma^{\prime \prime}\left(s_{p}\right) \frac{d s_{p}}{d \theta}= & \frac{\frac{1-\beta}{\beta} \frac{w^{-\zeta}}{1+\tau} c}{\Delta}\left(\rho\left(1-b^{1-\zeta}\right) w^{-\zeta}+\left(1-((1-p) b)^{1-\zeta}\right) w^{-\zeta}\left(\lambda\left(\sigma-s_{u}\right)+\mu s_{u}\right)+\right. \\
& +\zeta \eta \frac{1-\beta}{\beta} \frac{w^{-(1+\zeta)}}{1+\tau} \frac{c \theta(\rho+\delta)}{\mu}\left[\mu s_{u}+\rho+\lambda\left(\sigma-s_{u}\right)\right]+ \\
& \left.+(\rho+\delta)(1-\eta)(p b)^{1-\zeta} w^{-\zeta}\right) \\
> & 0
\end{aligned}
$$


if $\sigma \geq s_{p}$. This is always true by the assumption that $\sigma \geq 1$ and $\lim _{s \rightarrow 1} \gamma^{\prime}(s)=$ $+\infty$. QED

Proof of lemma 5. We show that the equations imply a unique solution in $(\theta, w)$ space. Given this solution $(\theta, w)$ equation (9) implies the solution for $x$. Substituting these values for $\theta, w$ and $x$ into equations (11) and (12) yields $s_{u}$ and $s_{p}$.

First, equation (14) implies a negative relation between $w$ and $\theta$. Lemma 4 shows that equations (9) - (12) imply a positive relation between $w$ and $\theta$. Second, consider the case where $\theta=0$. Then equation (14) implies an intercept in $(\theta, w)$ space equal to $\left.w\right|_{\theta=0}=\frac{y-\tau_{a}}{1+\tau}$. On the other hand, equations (9) and (10) imply as intercept $\left.w\right|_{\theta=0}=0$. Finally, taking the limit of $\theta \rightarrow+\infty$ in equation (14) yields $\left.\lim _{\theta \rightarrow+\infty} w\right|_{\text {in (14) }}=-\infty$. This proves that an equilibrium always exists in $(\theta, w)$ space and that it is unique. QED

Proof of lemma 6. For given equilibrium values of $\theta, s_{u}$ and $s_{p}$, the following equations of motion hold, where $\dot{u}_{u}$ and $\dot{u}_{p}$ denote the derivatives with respect to time.

$$
\begin{aligned}
\dot{u}_{u} & =\delta e-\left(\mu s_{u}+\lambda\left(\sigma-s_{u}\right)\right) u_{u} \\
\dot{u}_{p} & =\lambda\left(\sigma-s_{u}\right) u_{u}-\mu s_{p} u_{p} \\
1 & =u_{u}+u_{p}+e
\end{aligned}
$$

Note that lemma 5 implies that $\theta, s_{u}$ and $s_{p}$ are determined independent of the values of $u_{u}, u_{p}$ and $e$. Hence in steady state, defined as $\dot{u}_{u}=\dot{u}_{p}=0$, we find that

$$
\begin{aligned}
\delta\left(1-u_{u}-u_{p}\right)-\left(\mu s_{u}+\lambda\left(\sigma-s_{u}\right)\right) u_{u} & =0 \\
\lambda\left(\sigma-s_{u}\right) u_{u}-\mu s_{p} u_{p} & =0
\end{aligned}
$$

Solving this system, using matrices, yields

$$
\begin{aligned}
\left(\begin{array}{l}
u_{u} \\
u_{p}
\end{array}\right) & =\left(\begin{array}{cc}
\delta+\mu s_{u}+\lambda\left(\sigma-s_{u}\right) & \delta \\
\lambda\left(\sigma-s_{u}\right) & -\mu s_{p}
\end{array}\right)^{-1}\left(\begin{array}{l}
\delta \\
0
\end{array}\right) \\
& =\frac{1}{\Delta}\left(\begin{array}{cc}
\mu s_{p} & \delta \\
\lambda\left(\sigma-s_{u}\right) & -\left(\delta+\mu s_{u}+\lambda\left(\sigma-s_{u}\right)\right)
\end{array}\right)\left(\begin{array}{l}
\delta \\
0
\end{array}\right)
\end{aligned}
$$

QED

Proof of proposition 7. In order to derive the expression for $\frac{d^{2} u_{u}}{d b^{2}}$, we need the signs of the expressions for $\frac{d^{2} w}{d b^{2}}, \frac{d^{2} \theta}{d b^{2}}$ and $\frac{d^{2} s_{u}}{d b^{2}}$ which are derived first. 
We write equations (9) (for the case where $\lambda=x=0$ ) and (14) as

$$
\begin{aligned}
\left(1-b^{1-\zeta}\right) \frac{w^{1-\zeta}}{1-\zeta}-\frac{1-\beta}{\beta} \frac{w^{-\zeta}}{1+\tau}(\rho+\delta) \frac{c \theta}{\mu(\theta)} & =\max _{s}\left\{-\gamma(s)+s \frac{1-\beta}{\beta} \frac{w^{-\zeta}}{1+\tau} c \theta\right\} \\
(1+\tau) w & =y-\tau_{a}-(\rho+\delta) \frac{c \theta}{\mu(\theta)}
\end{aligned}
$$

Linearizing these equations in $w, \theta$ and $b$ yields

$$
\left(\begin{array}{ll}
\Xi & -\frac{1-\beta}{\beta} \frac{w^{-\zeta}}{1+\tau} c\left(\frac{\rho+\delta}{\mu(\theta)}(1-\eta)+s\right) \\
1+\tau & \frac{\rho+\delta}{\mu(\theta)}(1-\eta) c
\end{array}\right)\left(\begin{array}{l}
d w \\
d \theta
\end{array}\right)=\left(\begin{array}{l}
b^{-\zeta} w^{1-\zeta} d b \\
0
\end{array}\right)
$$

where

$$
\Xi \equiv\left(1-b^{1-\zeta}\right) w^{-\zeta}+\zeta \frac{1-\beta}{\beta} \frac{w^{-(1+\zeta)}}{1+\tau}(\rho+\delta) \frac{c \theta}{\mu}+\zeta s \frac{1-\beta}{\beta} \frac{w^{-(1+\zeta)}}{1+\tau} c \theta
$$

Hence

$$
\left(\begin{array}{l}
\frac{d w}{d b} \\
\frac{d \theta}{d b}
\end{array}\right)=\frac{1}{\Delta}\left(\begin{array}{ll}
\frac{\rho+\delta}{\mu(\theta)}(1-\eta) c & \frac{1-\beta}{\beta} \frac{w^{-\zeta}}{1+\tau} c\left(\frac{\rho+\delta}{\mu(\theta)}(1-\eta)+s\right) \\
-(1+\tau) & \Xi
\end{array}\right)\left(\begin{array}{l}
b^{-\zeta} w^{1-\zeta} \\
0
\end{array}\right)
$$

with

$$
\Delta \equiv \Xi \frac{\rho+\delta}{\mu(\theta)}(1-\eta) c+\frac{1-\beta}{\beta} w^{-\zeta} c\left(\frac{\rho+\delta}{\mu(\theta)}(1-\eta)+s\right)>0
$$

So we can write

$$
\begin{aligned}
\frac{d w}{d b} & =\frac{\frac{\rho+\delta}{\mu(\theta)}(1-\eta) c b^{-\zeta} w^{1-\zeta}}{\Delta}>0 \\
\frac{d \theta}{d b} & =\frac{-(1+\tau) b^{-\zeta} w^{1-\zeta}}{\Delta}<0
\end{aligned}
$$

It is routine to verify that $\frac{d w}{d b}$ can be rewritten as

$$
\frac{d w}{d b}=\frac{b^{-\zeta} w}{1-b^{1-\zeta}+\zeta \frac{1-\beta}{\beta} \frac{w^{-1}}{1+\tau} \frac{c \theta}{\mu(\theta)}(\rho+\delta+s \mu(\theta))+\frac{1-\beta}{\beta}\left(1+\frac{s \mu(\theta)}{(\rho+\delta)(1-\eta)}\right)}
$$

To find $\frac{d^{2} w}{d b^{2}}$, first note that the denominator in (16) is decreasing in $b$, because $\frac{d w}{d b}>0, \frac{d \theta}{d b}<0$ and $\frac{d s}{d b}<0$ as derived below. Thus a sufficient condition for $\frac{d^{2} w}{d b^{2}}>0$ is that the numerator in (16) is increasing in $b$. Clearly, this is the case if $\zeta=0$.

Similarly, rewrite $\frac{d \theta}{d b}$ as

$$
\frac{d \theta}{d b}=\frac{-(1+\tau)}{(\rho+\delta)(1-\eta) c} \frac{\mu(\theta) b^{-\zeta} w}{1-b^{1-\zeta}+\zeta \frac{1-\beta}{\beta} \frac{w^{-1}}{1+\tau} \frac{c \theta}{\mu(\theta)}(\rho+\delta+s \mu(\theta))+\frac{1-\beta}{\beta}\left(1+\frac{s \mu(\theta)}{(\rho+\delta)(1-\eta)}\right)}
$$


As noted above, the denominator is decreasing in $b$. Hence a sufficient condition for $\frac{d^{2} \theta}{d b^{2}}<0$ is that the expression $\mu(\theta) b^{-\zeta} w$ in the numerator is increasing in $b$. That is,

$$
\begin{aligned}
& \mu(\theta) b^{-\zeta} w\left(-\zeta b^{-1}+\frac{\eta}{\theta} \frac{d \theta}{d b}+w^{-1} \frac{d w}{d b}\right) \\
= & \mu(\theta) b^{-\zeta} w\left(-\zeta b^{-1}+\frac{b^{-\zeta} w^{-\zeta}}{\Delta \theta}\left[-\eta(1+\tau) w+(1-\eta)(\rho+\delta) \frac{c \theta}{\mu(\theta)}\right]\right) \\
= & \mu(\theta) b^{-\zeta} w\left(-\zeta b^{-1}+\frac{b^{-\zeta} w^{-\zeta}}{\Delta \theta}\left[-\eta\left(y-\tau_{a}\right)+(\rho+\delta) \frac{c \theta}{\mu(\theta)}\right]\right)
\end{aligned}
$$

which is positive if $\zeta=\eta=0$.

Next, we turn to the effect of $b$ on $s$. From the first order condition for $s$ we get

$$
\gamma^{\prime}(s)=\frac{1-\beta}{\beta} \frac{w^{-\zeta}}{1+\tau} c \theta
$$

Hence $\frac{d s}{d b}$ follows from

$$
\gamma^{\prime \prime}(s) \frac{d s}{d b}=\frac{1-\beta}{\beta} \frac{c}{1+\tau}\left(-\zeta w^{-(1+\zeta)} \theta \frac{d w}{d b}+w^{-\zeta} \frac{d \theta}{d b}\right)<0
$$

Differentiating this again with respect to $b$ yields

$$
\begin{aligned}
\gamma^{\prime \prime}(s) \frac{d^{2} s}{d b^{2}}= & \overbrace{-\gamma^{\prime \prime \prime}(s)\left(\frac{d s}{d b}\right)^{2}+\frac{1-\beta}{\beta} \frac{c}{1+\tau} w^{-\zeta} \frac{d^{2} \theta}{d b^{2}}}^{<0}+ \\
& +\zeta \frac{1-\beta}{\beta} \frac{c}{1+\tau}\left((1+\zeta) w^{-(2+\zeta)} \theta\left(\frac{d w}{d b}\right)^{2}-w^{-(1+\zeta)} \theta \frac{d^{2} w}{d b^{2}}\right. \\
& \left.-2 w^{-(1+\zeta)} \frac{d w}{d b} \frac{d \theta}{d b}\right)
\end{aligned}
$$

Hence $\frac{d^{2} s}{d b^{2}}<0$ if $\zeta=0$ and $\frac{d^{2} \theta}{d b^{2}}<0$.

Finally, the effect on unemployment can be found as follows. With $\lambda=0$, unemployment equals $u_{u}=\frac{\delta}{\delta+\mu(\theta) s_{u}}$. Differentiating with respect to $b$ yields

$$
\frac{d u_{u}}{d b}=-\frac{\delta}{\left(\delta+\mu(\theta) s_{u}\right)^{2}}\left(\mu^{\prime}(\theta) \frac{d \theta}{d b} s_{u}+\mu(\theta) \frac{d s_{u}}{d b}\right)>0
$$

Then the second derivative can be written as

$$
\frac{d^{2} u_{u}}{d b^{2}}=\frac{2 \delta}{\left(\delta+\mu(\theta) s_{u}\right)^{3}}(\overbrace{\left[\mu^{\prime}(\theta) s_{u} \frac{d \theta}{d b}-\mu(\theta) \frac{d s}{d b}\right]^{2}}^{>0}+\mu^{\prime}(\theta) \overbrace{\frac{d \theta}{d b} \frac{d s_{u}}{d b}}^{>0} \overbrace{\left(3 s_{u} \mu(\theta)-\delta\right)}^{(*)})+
$$




$$
+\frac{\delta}{\left(\delta+\mu(\theta) s_{u}\right)^{2}} \underbrace{\left[\left(-\mu^{\prime \prime}(\theta)\left(\frac{d \theta}{d b}\right)^{2} s_{u}+\mu^{\prime}(\theta)\left(-\frac{d^{2} \theta}{d b^{2}}\right) s_{u}+\mu(\theta)\left(-\frac{d^{2} s_{u}}{d b^{2}}\right)\right]\right.}_{>0}
$$

A sufficient condition for this second derivative to be positive is that the expression labelled $\left(^{*}\right)$ is positive. Dividing this expression by $(\delta+\mu(\theta) s)$ yields $3(1-u)=\frac{3 \mu(\theta) s_{u}}{\delta+\mu(\theta) s_{u}}>\frac{\delta}{\delta+\mu(\theta) s_{u}}=u$. In other words, the expression $\left(^{*}\right)$ is positive if and only if $u<\frac{3}{4}$.QED

Proof of proposition 8 To show that $\frac{d e}{d \lambda}>\left|\frac{d e}{d b}\right|$ under the assumption that $\left|\frac{d w}{d \lambda}\right|=\frac{d w}{d b}$, we make three steps. First, consider the effect on $\theta$. From equation (14) we know that

$$
\begin{aligned}
& \frac{d \theta}{d b}=\frac{d \theta}{d w} \frac{d w}{d b} \\
& \frac{d \theta}{d \lambda}=\frac{d \theta}{d w} \frac{d w}{\lambda}
\end{aligned}
$$

Because of the assumption $\left|\frac{d w}{d \lambda}\right|=\frac{d w}{d b}$, we see that the effect of a reduction in $b$ on $\theta$ is the same as the effect of a rise in $\lambda$.

Second, differentiating equation (11) with respect to $b$ we find

$$
\gamma^{\prime \prime}\left(s_{u}\right) \frac{d s_{u}}{d b}=\left(-\zeta \frac{1-\beta}{\beta} \frac{w^{-(1+\zeta)}}{1+\tau} c \theta+\frac{1-\beta}{\beta} \frac{w^{-\zeta}}{1+\tau} c \frac{d \theta}{d w}\right) \frac{d w}{d b}
$$

Similarly, differentiating the same equation with respect to $\lambda$ and evaluating at $\lambda=0$ yields

$$
\gamma^{\prime \prime}\left(s_{u}\right) \frac{d s_{u}}{d \lambda}=\left(-\zeta \frac{1-\beta}{\beta} \frac{w^{-(1+\zeta)}}{1+\tau} c \theta+\frac{1-\beta}{\beta} \frac{w^{-\zeta}}{1+\tau} c \frac{d \theta}{d w}\right) \frac{d w}{d \lambda}+x
$$

Because $x>0$ we see that the effect of a reduction in $b$ on $s_{u}$ is smaller than the effect of a rise in $\lambda$ on $s_{u}$.

Third, because the effect of $\lambda$ is evaluated at $\lambda=0$, lemma 2 implies that $s_{p}>s_{u}$. In other words, the search intensity of the unemployed with a penalty exceeds the search intensity of the unemployed without a penalty, which (from equations (18) and (19)) exceeds the search intensity of the unemployed which experience a generic fall in $b$.

Since employment $e$ is rising in $\theta, s_{u}$ and $s_{p}$, we find that under the assumptions made $\frac{d e}{d \lambda}>\left|\frac{d e}{d b}\right| \cdot$ QED 